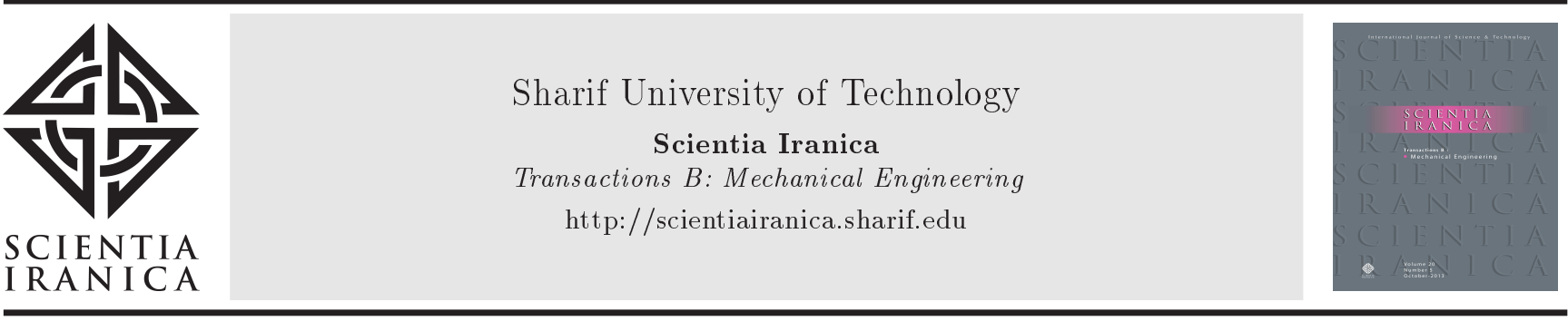

\title{
Nonlinear free vibration analysis of functionally graded plate resting on elastic foundation in thermal environment using higher-order shear deformation theory
}

\author{
S. Parida* and S.C. Mohanty \\ Department of Mechanical Engineering, NIT Rourkela, Rourkela, 769008, India. \\ Received 24 April 2017; received in revised form 4 September 2017; accepted 5 March 2018
}

\author{
KEYWORDS \\ Functionally graded \\ plate; \\ Green-Lagrange \\ nonlinearity; \\ Elastic foundation; \\ Thermal environment; \\ Simple power law \\ distribution.
}

\begin{abstract}
This paper deals with nonlinear vibration analysis of a functionally graded plate resting on Pasternak elastic foundation in a thermal environment. A mathematical model is developed based on a higher-order shear deformation theory using Green-Lagrange type nonlinearity. The model includes all the nonlinear terms to obtain a general form and to present the original flexure of the plate. The material properties are considered as temperature dependent and graded along thickness direction following a simple power law distribution in terms of volume fraction of the constituents. The compression/traction free condition is employed to obtain a simplified model with seven parameters instead of nine parameters. The plate model has been discretized into $C^{0}$ eight-noded quadratic elements with seven degrees of freedom per node. The governing equation of the functionally graded plate has been derived using Hamilton's principle and solved by a direct iterative method. The present model is validated by comparing the obtained results with those published in the literature. The effects of volume fraction index, aspect ratio, thickness ratio, support conditions, elastic foundation modulus, and temperature on the nonlinear frequencies of the functionally graded plates are discussed. It has been found that the intermediate material property does not necessarily give intermediate nonlinear frequency.
\end{abstract}

(C) 2019 Sharif University of Technology. All rights reserved.

\section{Introduction}

The Functionally Graded Material (FGM), well known as the high-performance heat-resistant material, was proposed in 1984 by a group of material scientists of Sendai area in Japan. FGM is microscopically inhomogeneous composite material composed of ce-

\footnotetext{
*. Corresponding author.

E-mail addresses: parida.smita10@gmail.com (S. Parida); scmohanty@nitrkl.ac.in (S.C. Mohanty)
}

ramic (the high-temperature side with good thermal resistance) and metal (the low-temperature side with superior fracture toughness), in which the material properties vary along the thickness direction obeying simple power law distribution that depends on the volume fraction of the constituent materials. Flat FGM plate subjected to an external load supported on the elastic foundation is a commonly used structure found in petrochemical, marine, aerospace, biomechanics as well as various mechanical, electrical, nuclear, and civil engineering. These structures are likely to undergo large amplitude vibration; thereby, their geometric 
nonlinear vibration analysis has gained considerable attention of the researchers since the last few decades. Akhavan et al. [1,2] obtained the exact solution for the buckling load and frequencies of Mindlin plate supported on an elastic foundation subjected to uniform and linearly distributed in-plane loading. The analysis procedure includes the first-order shear deformation theory for the plate-foundation interaction model. Baferani et al. [3] employed an analytical approach to vibration analysis of an FGM rectangular plate resting on Pasternak elastic foundation using Hamilton's principle for the Levy type boundary conditions. They considered the displacement field based on the third-order shear deformation theory. Bodaghi and Saidi [4] achieved an exact analytical solution for the buckling of the FGM plate using classical plate theory and derived the governing equations based on the exact neutral surface position. Chien and Chen [5] studied the nonlinear vibration of the laminated plate resting on a nonlinear Winkler-type elastic foundation. Galerkin method and the Runge-Kutta method were employed to calculate the frequency ratio of an initially stressed laminated plate. Governing equations were derived using the variational principle. Duc et al. [6] calculated the numerical results of nonlinear thermal dynamic response and nonlinear vibration of thick FGM plates using a third-order shear deformation theory and stress function by the Runge-kutta method. Gajendar [7] employed a modified Galerkin method to derive a nonlinear differential equation in terms of elliptic function. Kiani et al. [8] presented a thermoelastic free vibration analysis of an FGM doubly curved panel using analytical hybrid Laplace-Fourier transformation based on the first-order shear deformation theory. Further, the analysis of the FGM doubly curved panel resting on the Pasternak-type elastic foundation was carried out by Kiani et al. [9]. Shen et al. [10] and Shen and Wang [11] presented a nonlinear vibration analysis of an FGM doubly curved panel resting on the elastic foundation in thermal environment based on the higher-order shear deformation theory and von Karman strain-displacement relationship, considering the micromechanics model like Voigt and Mori-Tanaka micromechanics model. Shen and Wang [12] presented the nonlinear vibration of the FGM cylindrical plate containing piezoelectric layers resting on the elastic foundation in a thermal environment based on the higher-order shear deformation theory. Huang et al. [13] presented an exact three-dimensional elasticity solution for the bending behavior of the FGM thick plate resting on Winkler-Pasternak elastic foundation using a state-space method in order to express the equations to condense first-order differential equations. Dehghan and Baradaran [14] proposed a coupled FEDQ for 3D analysis of the thick rectangular plate resting on the elastic foundation and discretized the plate geometry into 2D finite-element mesh. Qin and Diao [15] developed Hybrid-Trefftz (HT) p-element for nonlinear analysis of Reissner-Mindlin plate resting on elastic foundation. Duc and Cong [16] investigated the nonlinear post-buckling behavior of symmetric SFGM plate resting on elastic foundation and subjected to thermo-mechanical loads using the Galerkin method. The model was developed in the framework of Reddy's third-order shear deformation plate theory and von-Karman type nonlinear equations. Fallah et al. [17] studied the free vibration analysis of moderately thick functionally graded plates supported on Winkler foundation using an extended Kantorovich method along with an infinite power series solution. Further, they presented nonlinear free vibration analysis of functionally graded beam resting on nonlinear elastic foundation using Galerkin one-parameter solution with von-Karman's strain displacement relation [18]. Taczala et al. [19] investigated the geometric nonlinear free vibration of the thick FGM plate in the thermal environment that is supported on a two-parameter foundation using FSDT and von Karman nonlinearity. Yang et al. [20] obtained the theoretical solution for a rectangular plate resting on elastic foundation with free edges by a reciprocal theorem method. Sundararajan et al. [21] employed von-Karman nonlinearity-based FSDT formulation to carry out the vibration analysis of the FGM plate in the thermal environment. Huang and Shen [22] presented the nonlinear vibration analysis of the FGM plate by incorporating HSDT that includes von-Karman-type nonlinearity. The nonlinear equations were solved by the improved perturbation technique. Civalek [23] employed the Discrete Singular Convolution (DSC), such as the Regularized Shanon's Kernel (RSK) and Lagrange Delta (LD) kernel, and a Harmonic Differential Quadrature (HDQ) method in order to derive the governing nonlinear partial differential equation of the plate on Winkler-Pasternak elastic foundation. Qin [24] presented the nonlinear analysis of Reissner plate resting on an elastic foundation by the boundary element method. Singha and Daripa [25] investigated the large amplitude flexural vibration of a composite plate subjected to periodic in-plane load employing HSDT with von-Karman nonlinearity. Thi and Duc [26] investigated the nonlinear stability of an FGM spherical shell on the elastic foundation in the thermal environment using FSDT and Galerkin method. Tornabene et al. [27] investigated the statics and dynamics of laminated doubly curved shells resting on Winkler-Pasternak elastic foundation using FSDT in conjunction with generalized differential quadrature. Tornabene et al. [28] proposed a 2D higher-order equivalent single-layer theory to determine the free vibration of doubly curved laminated composite shells with different curvatures. Szekrenyes [29,30] introduced the theorem of autocontinuity to attain continuity 
between the laminated and delaminated portions and proposed the method of four equivalent single layers for modeling a delaminated orthotropic composite plate using second- and third-order laminated plate theories.

According to the above review, it is clear that many studies have already been reported on the nonlinear vibration behavior of FGM plates on elastic foundation using von-Karman-type nonlinear strain in the framework of FSDT and HSDT mid-plane kinematics that solely considers the transverse displacement. Based on this author's knowledge, no study has been carried out in open literature on geometric nonlinear free vibration behavior of the FGM plate resting on the two-parameter elastic foundation based on HSDT mid-plane kinematics and GreenLagrange nonlinearity, considering moderately large displacements and rotations, including temperaturedependent material properties, due to the nonlinear temperature rise. Hence, the present study aims to predict an accurate geometric nonlinear analysis by developing a mathematical model that includes the Green-Lagrange nonlinear strains in the framework of HSDT. Based on HSDT, a modified displacement field with $C^{0}$ continuity has been employed that satisfies the traction-free boundary condition. The GreenLagrange nonlinearity includes all nonlinear higherorder terms that have been incorporated to attain the original flexure and enhance the flexibility of the plate (general case) structure resting on the two-parameter elastic foundation in the thermal environment. The governing equations are obtained through Hamilton's principle, and the preferred nonlinear responses are computed by the direct iterative method. The plate has been discretized using an eight-noded quadratic serendipity element with seven degrees of freedom per node. The model has been validated by comparing it with results available in the literature. The effects of various parameters such as volume fraction index, aspect ratio, thickness ratio, foundation modulus $\left(K_{w}\right.$, $K_{s}$ ), temperature, and different boundary conditions on frequency parameters are discussed in detail.

\section{Material property of FGM}

Consider an FGM plate with geometric dimensions of length $a$, width $b$, and thickness $h$ resting on a two-parameter elastic foundation (a combination of an uncoupled spring layer and a shear layer at its top), as shown in Figure 1.

According to the power law distribution, the volume fraction of the ceramic constituent (top) can be written as follows:

$$
V_{c}=\left(\frac{z}{h}+0.5\right)^{n}
$$

where $z$ is the thickness co-ordinate $(-h / 2 \leq z \leq$ $h / 2)$, and $n$ is the power law index $(0 \leq n \leq \infty)$

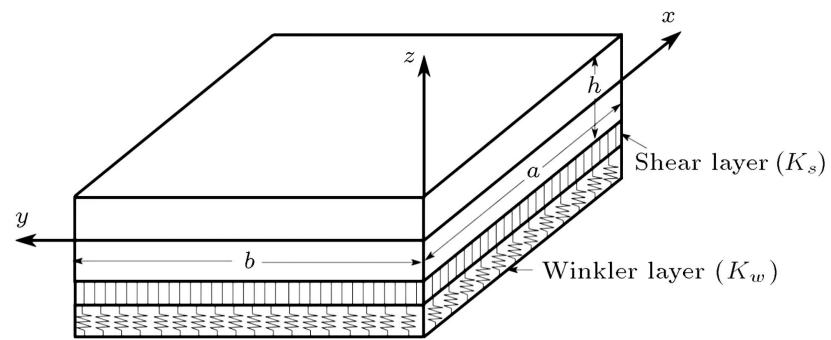

Figure 1. A functionally graded material plate resting on Pasternak foundation.

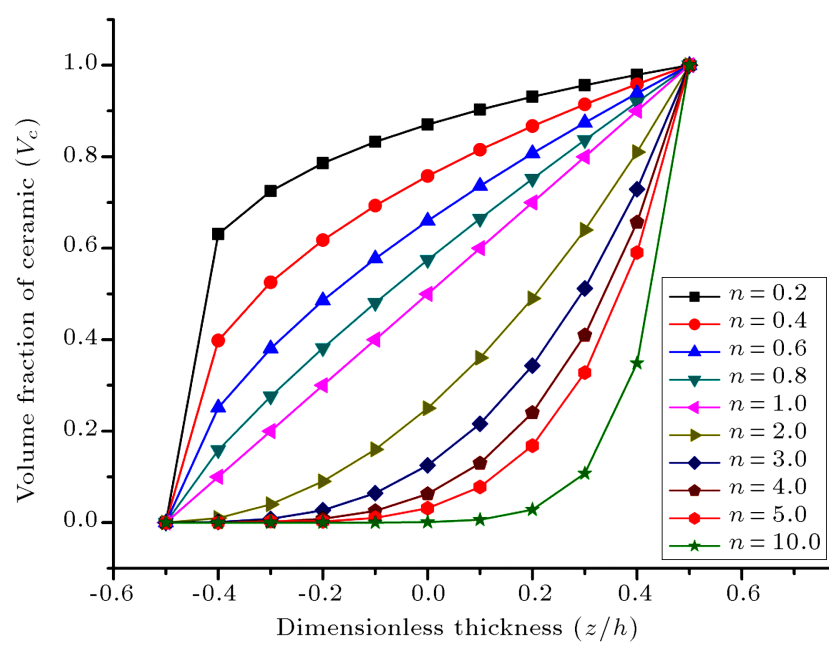

Figure 2. Variation of ceramic volume fraction, $V_{c}$, through the dimensionless thickness $(Z / h)$.

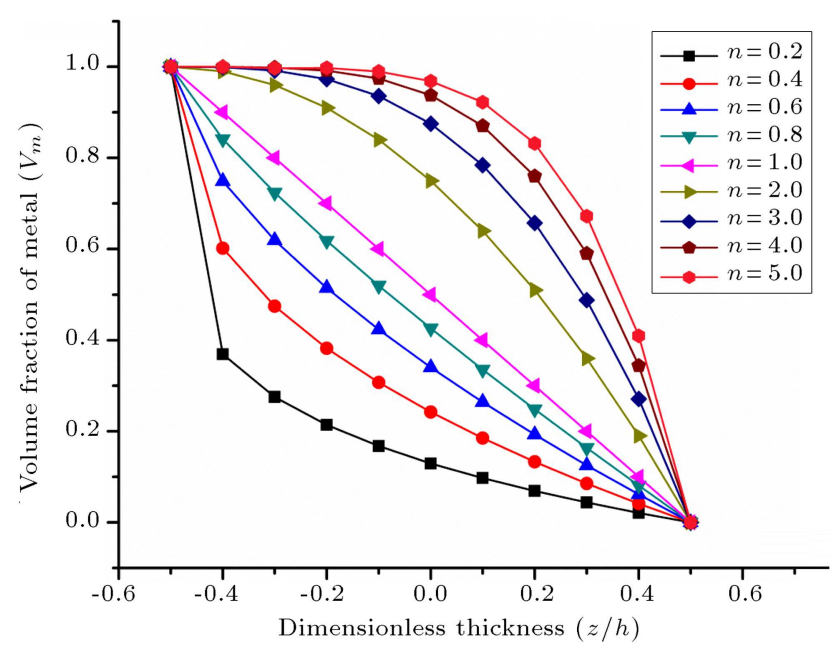

Figure 3. Variation of metal volume fraction, $V_{m}$, through the dimensionless thickness $(Z / h)$.

responsible for generating an infinite number of varying compositions between two phases. The effect of power law index on the volume fraction of ceramic and metal is shown in Figures 2 and 3.

The effective properties such as Young's modulus, $E_{e f}$, Poisson's ratio, $v_{e f}$, thermal expansion coefficient, $\alpha_{e f}$, mass density, $\rho_{e f}$, and thermal conductivity, $k_{e f}$, 
are temperature dependent and are expressed in a nonlinear function of temperature [31] as per the rule of mixture (Voigt rule).

$$
P_{e f}=P_{b}(T)+\left[P_{t}(T)-P_{b}(T)\right]\left(\frac{z}{h}+\frac{1}{2}\right)^{n},
$$

where $P_{t}$ and $P_{b}$ are the properties of constituents at the top and the bottom of the plate. In this paper, metal is at the bottom $(z=-h / 2)$, and ceramic is at the top $(z=+h / 2)$.

$$
\begin{aligned}
& P_{m}(T) \text { and } P_{c}(T) \\
& \quad=P_{0}\left(P_{-1} T^{-1}+1+P_{1} T+P_{2} T^{2}+P_{3} T^{3}\right),
\end{aligned}
$$

where $P_{0}, P_{-1}, P_{1}, P_{2}$, and $P_{3}$ are the coefficients of temperature $T$ (in $\mathrm{K}$ ) and are unique for the constituent materials. The temperature-dependent material properties $(E, \alpha, \rho, k)$ can be obtained through Eqs. (4)-(7):

$$
\begin{aligned}
& E(z, T)=E_{m}(T)+\left[E_{c}(T)-E_{m}(T)\right]\left(\frac{z}{h}+\frac{1}{2}\right)^{n}, \\
& \alpha(z, T)=\alpha_{m}(T)+\left[\alpha_{c}(T)-\alpha_{m}(T)\right]\left(\frac{z}{h}+\frac{1}{2}\right)^{n}, \\
& \rho(z, T)=\rho_{m}(T)+\left[\rho_{c}(T)-\rho_{m}(T)\right]\left(\frac{z}{h}+\frac{1}{2}\right)^{n}, \\
& k(z, T)=k_{m}(T)+\left[k_{c}(T)-k_{m}(T)\right]\left(\frac{z}{h}+\frac{1}{2}\right)^{n},
\end{aligned}
$$

where subscripts $m$ and $c$ refer to metal and ceramic constituents, respectively.

\section{Theoretical formulation}

\subsection{Displacement field}

The displacement field considering HSDT is assumed, as given in $[29,30,32]$ :

$$
\begin{aligned}
u(x, y, z)= & u_{0}(x, y)+z \theta_{y}(x, y)+z^{2} \vartheta_{x}(x, y) \\
& +z^{3} \psi_{x}(x, y), \\
v(x, y, z)= & v_{0}(x, y)-z \theta_{x}(x, y)+z^{2} \vartheta_{y}(x, y) \\
& +z^{3} \psi_{y}(x, y), \\
w(x, y, z)= & w_{0}(x, y),
\end{aligned}
$$

where $u, v$, and $w$ represent the displacements of the point along the $(x, y, z)$ coordinates. $u_{0}, v_{0}, w_{0}$ and $\theta_{x}$, $\theta_{y}$ denote the in-plane displacements and the rotations of transverse normal to the midplane about $x$ and $y$ axes, respectively. Functions $\vartheta_{x}, \vartheta_{y}, \psi_{x}$ and $\psi_{y}$ are the higher-order terms in Taylor series expansion defined in the mid-plane of the plate.
A modified displacement model can be derived by implementing the assumption of zero transverse shear stress $\left(\tau_{x z}, \tau_{y z}\right)$ across the interface (the traction-free condition). Hence, the shear strain is considered zero and is presented as follows:

$$
\begin{aligned}
& \gamma_{x z}=\frac{\partial u}{\partial z}+\frac{\partial w}{\partial x}=\theta_{y}+2 z \vartheta_{x}+3 z^{2} \psi_{x}+\frac{\partial w_{0}}{\partial x}=0 \\
& \gamma_{y z}=\frac{\partial v}{\partial z}+\frac{\partial w}{\partial y}=-\theta_{x}+2 z \vartheta_{y}+3 z^{2} \psi_{y}+\frac{\partial w_{0}}{\partial y}=0 .
\end{aligned}
$$

By simplifying Eq. (8), the displacement model can be modified. Further, to obtain $C^{0}$ continuity, two new variables $\beta_{x}$ and $\beta_{y}$ are introduced by using a relation given in Appendix (Eq. (A.1)).

The modified displacement model with $C^{0}$ continuity is presented as follows:

$$
\begin{aligned}
& u=u_{0}+z \theta_{y}-c_{1} z^{3}\left(\theta_{y}+\beta_{x}\right), \\
& v=v_{0}-z \theta_{x}-c_{1} z^{3}\left(-\theta_{x}+\beta_{y}\right), \\
& w=w_{0},
\end{aligned}
$$

where $c_{1}=4 / 3 h^{2}$ and $u, v, w, \theta_{x}, \theta_{y}, \beta_{x}$, and $\beta_{y}$ are considered as field variables for structural deformation.

\subsection{Nonlinear temperature rise}

The temperature distribution along the thickness direction can be obtained by solving a one-dimensional steady-state heat transfer equation. The steady-state heat conduction equation for the temperature through the thickness is given by:

$$
-\frac{d}{d z}\left(k(z, T) \frac{d T}{d z}\right)=0 .
$$

Further, Eq. (11) can be solved by imposing the boundary condition of $T=T_{m}$ at $z=-h / 2$ and $T=T_{c}$ at $z=h / 2$.

The variation of temperature in an FGM plate through the thickness is expressed as follows:

$$
T(z)=T_{m}-\left(T_{c}-T_{m}\right) \frac{\int_{-h / 2}^{z}(1 / k(z, T)) d z}{\int_{-h / 2}^{h / 2}(1 / k(z, T)) d z} .
$$

The solution to the above equation as obtained by using polynomial series is as follows:

$$
\begin{aligned}
T(z)= & T_{m}+\frac{\Delta T}{\bar{P}}\left[\left(\frac{z}{h}+\frac{1}{2}\right)\right. \\
& -\frac{k_{c m}}{(n+1) k_{m}}\left(\frac{z}{h}+\frac{1}{2}\right)^{n+1} \\
& +\frac{k_{c m}^{2}}{(2 n+1) k_{m}^{2}}\left(\frac{z}{h}+\frac{1}{2}\right)^{2 n+1}
\end{aligned}
$$




$$
\begin{aligned}
& -\frac{k_{c m}^{3}}{(3 n+1) k_{m}^{3}}\left(\frac{z}{h}+\frac{1}{2}\right)^{3 n+1} \\
& +\frac{k_{c m}^{4}}{(4 n+1) k_{m}^{4}}\left(\frac{z}{h}+\frac{1}{2}\right)^{4 n+1} \\
& \left.-\frac{k_{c m}^{5}}{(5 n+1) k_{m}^{5}}\left(\frac{z}{h}+\frac{1}{2}\right)^{5 n+1}\right],
\end{aligned}
$$

where:

$$
\begin{aligned}
\bar{P}=1 & -\frac{k_{c m}}{(n+1) k_{m}}+\frac{k_{c m}^{2}}{(2 n+1) k_{m}^{2}}-\frac{k_{c m}^{3}}{(3 n+1) k_{m}^{3}} \\
& +\frac{k_{c m}^{4}}{(4 n+1) k_{m}^{4}}-\frac{k_{c m}^{5}}{(5 n+1) k_{m}^{5}},
\end{aligned}
$$

and:

$$
k_{c m}=k_{c}-k_{m} \text {. }
$$

\subsection{Nonlinear formulation}

The strain developed in the FGM plate is the sum of linear and nonlinear strains. The nonlinear strain presents the Green-Lagrange strain displacement relation associated with moderately large displacements, and rotations include all the field variables as shown in relations given below:

$$
\{\varepsilon\}=\left\{\varepsilon_{L}\right\}+\left\{\varepsilon_{N L}\right\} .
$$

The above equation can be presented in the form of linear and nonlinear parts:

$$
\begin{aligned}
& \left\{\begin{array}{c}
\varepsilon_{x x} \\
\varepsilon_{y y} \\
\gamma_{x y} \\
\gamma_{x z} \\
\gamma_{y z}
\end{array}\right\}=\left\{\begin{array}{c}
u_{, x} \\
v_{, y} \\
u_{, y}+v_{, x} \\
u_{, z}+w_{, x} \\
v_{, z}+w_{, y}
\end{array}\right\} \\
& +\left\{\begin{array}{c}
\frac{1}{2}\left\{\left(u_{, x}\right)^{2}+\left(v_{, x}\right)^{2}+\left(w_{, x}\right)^{2}\right\} \\
\frac{1}{2}\left\{\left(u_{, y}\right)^{2}+\left(v_{, y}\right)^{2}+\left(w_{, y}\right)^{2}\right\} \\
\left\{\left(u_{, x}\right)\left(u_{, y}\right)+\left(v_{, x}\right)\left(v_{, y}\right)+\left(w_{, x}\right)\left(w_{, y}\right)\right\} \\
\left\{\left(u_{, x}\right)\left(u_{, z}\right)+\left(v_{, x}\right)\left(v_{, z}\right)+\left(w_{, x}\right)\left(w_{, z}\right)\right\} \\
\left\{\left(u_{, y}\right)\left(u_{, z}\right)+\left(v_{, y}\right)\left(v_{, z}\right)+\left(w_{, y}\right)\left(w_{, z}\right)\right\}
\end{array}\right\} .
\end{aligned}
$$

By substituting Eq. (10) in Eq. (16), the strain displacement relation of the plate can be expressed as follows:

$$
\left\{\varepsilon_{L}\right\}=\left\{\begin{array}{l}
\varepsilon_{1}^{0} \\
\varepsilon_{2}^{0} \\
\varepsilon_{6}^{0} \\
\varepsilon_{5}^{0} \\
\varepsilon_{4}^{0}
\end{array}\right\}+z\left\{\begin{array}{l}
\kappa_{1}^{1} \\
\kappa_{2}^{1} \\
\kappa_{6}^{1} \\
\kappa_{5}^{1} \\
\kappa_{4}^{1}
\end{array}\right\}+z^{2}\left\{\begin{array}{c}
\kappa_{1}^{2} \\
\kappa_{2}^{2} \\
\kappa_{6}^{2} \\
\kappa_{5}^{2} \\
\kappa_{4}^{2}
\end{array}\right\}+z^{3}\left\{\begin{array}{c}
\kappa_{1}^{3} \\
\kappa_{2}^{3} \\
\kappa_{6}^{3} \\
\kappa_{5}^{3} \\
\kappa_{4}^{3}
\end{array}\right\},
$$

$$
\begin{aligned}
&\left\{\varepsilon_{N L}\right\}= \frac{1}{2}\left\{\begin{array}{l}
\varepsilon_{1}^{n l 0} \\
\varepsilon_{2}^{n l 0} \\
\varepsilon_{6}^{n l 0} \\
\varepsilon_{5}^{n l 0} \\
\varepsilon_{4}^{n l 0}
\end{array}\right\}+\frac{z}{2}\left\{\begin{array}{l}
\kappa_{1}^{n l 1} \\
\kappa_{2}^{n l 1} \\
\kappa_{6}^{n l 1} \\
\kappa_{5}^{n l 1} \\
\kappa_{4}^{n l 1}
\end{array}\right\} \\
&+ \frac{z^{2}}{2}\left\{\begin{array}{l}
\kappa_{1}^{n l 2} \\
\kappa_{2}^{n l 2} \\
\kappa_{6}^{n l 2} \\
\kappa_{5}^{n l 2} \\
\kappa_{4}^{n l 2}
\end{array}\right\}+\frac{z^{3}}{2}\left\{\begin{array}{l}
\kappa_{1}^{n l 3} \\
\kappa_{2}^{n l 3} \\
\kappa_{6}^{n l 3} \\
\kappa_{5}^{n l 3} \\
\kappa_{4}^{n l 3}
\end{array}\right\} \\
&+\frac{z^{4}}{2}\left\{\begin{array}{l}
\kappa_{1}^{n l 4} \\
\kappa_{2}^{n l 4} \\
\kappa_{6}^{n l 4} \\
\kappa_{5}^{n l 4} \\
\kappa_{4}^{n l 4}
\end{array}\right\}+\frac{z^{5}}{2}\left\{\begin{array}{l}
\kappa_{1}^{n l 5} \\
\kappa_{2}^{n l 5} \\
\kappa_{6}^{n l 5} \\
\kappa_{5}^{n l 5} \\
\kappa_{4}^{n l 5}
\end{array}\right\} \\
&+\frac{z^{6}}{2}\left\{\begin{array}{l}
\kappa_{1}^{n l 6} \\
\kappa_{2}^{n l 6} \\
\kappa_{6}^{n l 6} \\
\kappa_{5}^{n l 6} \\
\kappa_{4}^{n l 6}
\end{array}\right\} .
\end{aligned}
$$

The individual strain terms are described in Appendix (Eq. (A.2)).

$$
\left\{\bar{\varepsilon}_{L}\right\}=\left\{\begin{array}{l}
\varepsilon_{1}^{0}, \varepsilon_{2}^{0}, \varepsilon_{6}^{0}, \varepsilon_{5}^{0}, \varepsilon_{4}^{0}, \kappa_{1}^{1}, \kappa_{2}^{1}, \kappa_{6}^{1}, \kappa_{5}^{1}, \kappa_{4}^{1}, \\
\kappa_{1}^{2}, \kappa_{2}^{2}, \kappa_{6}^{2}, \kappa_{5}^{2}, \kappa_{4}^{2}, \kappa_{1}^{3}, \kappa_{2}^{3}, \kappa_{6}^{3}, \kappa_{5}^{3}, \kappa_{4}^{3}
\end{array}\right\},
$$

and:

$$
\left\{\bar{\varepsilon}_{N L}\right\}=\frac{1}{2}\left\{\begin{array}{l}
\varepsilon_{1}^{n l 0}, \varepsilon_{2}^{n l 0}, \varepsilon_{6}^{n l 0}, \varepsilon_{5}^{n l 0}, \varepsilon_{4}^{n l 0}, \kappa_{1}^{n l 1}, \\
\kappa_{2}^{n l 1}, \kappa_{6}^{n l 1}, \kappa_{5}^{n l 1}, \kappa_{4}^{n l 1}, \kappa_{1}^{n l 2}, \kappa_{2}^{n l 2}, \\
\kappa_{6}^{n l 2}, \kappa_{5}^{n l 2}, \kappa_{4}^{n l 2}, \kappa_{1}^{n l 3}, \kappa_{2}^{n l 3}, \kappa_{6}^{n l 3}, \\
\kappa_{5}^{n l 3}, \kappa_{4}^{n l 3}, \kappa_{1}^{n l 4}, \kappa_{2}^{n l 4}, \kappa_{6}^{n l 4}, \kappa_{5}^{n l 4} \\
\kappa_{4}^{n l 4}, \kappa_{1}^{n l 5}, \kappa_{2}^{n l 5}, \kappa_{6}^{n l 5}, \kappa_{5}^{n l 5}, \kappa_{4}^{n l 5}, \\
\kappa_{1}^{n l 6}, \kappa_{2}^{n l 6}, \kappa_{6}^{n l 6}, \kappa_{5}^{n l 6}, \kappa_{4}^{n l 6}
\end{array}\right\}
$$

$\left\{\bar{\varepsilon}_{L}\right\}$ and $\left\{\bar{\varepsilon}_{N L}\right\}$ are the mid-plane linear and nonlinear strain terms. Superscripts 0,1 and $n l 0, n l 1$ denote membrane and bending terms; $2-3$ and $n l 2-n l 6$ represent higher-order terms, respectively.

\subsection{Thermo-elastic constitutive relations}

The constitutive equation for the FGM plate subjected to thermal load is presented as follows:

$$
\{\sigma\}=[\bar{Q}]\{\varepsilon-\alpha \Delta T\},
$$

where $\{\sigma\}$ and $\{\varepsilon\}$ are the stress and strain vectors, $[\bar{Q}]$ is the transformed reduced elastic stiffness matrix, $\Delta T$ is the increment of the temperature of the ceramic interface over reference temperature $T_{0}$, and $\alpha$ is the coefficient of the thermal expansion.

Further, Eq. (20) can be expanded and rewritten as follows: 


$$
\begin{aligned}
\left\{\begin{array}{l}
\sigma_{x x} \\
\sigma_{y y} \\
\tau_{x y} \\
\tau_{x z} \\
\tau_{y z}
\end{array}\right\}= & {\left[\begin{array}{ccccc}
Q_{11} & Q_{12} & 0 & 0 & 0 \\
Q_{21} & Q_{22} & 0 & 0 & 0 \\
0 & 0 & Q_{66} & 0 & 0 \\
0 & 0 & 0 & Q_{44} & 0 \\
0 & 0 & 0 & 0 & Q_{55}
\end{array}\right] } \\
& \left(\left\{\begin{array}{c}
\varepsilon_{x x} \\
\varepsilon_{y y} \\
\gamma_{x y} \\
\gamma_{x z} \\
\gamma_{y z}
\end{array}\right\}-\left\{\begin{array}{l}
1 \\
1 \\
0 \\
0 \\
0
\end{array}\right\} \alpha(z, T) \Delta T\right),
\end{aligned}
$$

where:

$$
\begin{aligned}
& Q_{11}=Q_{22}=\frac{E(z, T)}{1-v(z, T)^{2}}, \\
& Q_{12}=Q_{21}=\frac{v(z, T) E(z, T)}{1-v(z, T)^{2}}, \\
& Q_{44}=Q_{55}=Q_{66}=\frac{E(z, T)}{2(1+v(z, T))},
\end{aligned}
$$

and $\Delta T$ is the temperature change for a stress-free state, $E(z, T)$ is the modulus, and $\alpha(z, T)$ is the coefficient of the thermal expansion.

\section{FEM model}

For the present analysis, the model is discretized using an eight-noded isoparametric quadratic element with seven degrees of freedom associated with each node for the finite element modeling. The field variables at any arbitrary point are related to the nodal field variables via shape functions $N_{i}$. The relation is presented below as in the study of Cook et al. [33]:

$$
\left\{\delta^{e}\right\}=\left\{u_{0}^{e}, v_{0}^{e}, w_{0}^{e}, \beta_{x}^{e}, \beta_{y}^{e}, \theta_{x}^{e}, \theta_{y}^{e}\right\},
$$

and:

$$
\{\delta\}=\sum_{i=1}^{8} N_{i}^{e}(\xi, \eta)\left\{\delta^{e}\right\},
$$

where $u_{0}^{e}, v_{0}^{e}, w_{0}^{e}, \beta_{x}^{e}, \beta_{y}^{e}, \theta_{x}^{e}, \theta_{y}^{e}$ are the field variables/degrees of freedom, $N_{i}^{e}(\xi, \eta)$ are the shape functions, and $\xi, \eta$ are the natural coordinates.

\section{The energy equations}

\subsection{Strain energy}

The strain energy of the plate can be expressed as follows:

$$
U=\frac{1}{2} \int_{V}\{\varepsilon\}^{T}\{\sigma\} d V
$$

The vectors of the strain component are:

$$
\begin{aligned}
& \{\sigma\}=[\bar{Q}]\{\varepsilon\}, \\
& \{\varepsilon\}=\left(B_{L}+\frac{1}{2} B_{N L}\right)\{\delta\}_{e} .
\end{aligned}
$$

By substituting the strain and stress vectors from Eq. (24) and (25) in Eq. (23), the expression can be rewritten as follows:

$$
\begin{aligned}
U & =\frac{1}{2} \int_{A}\left(\{\varepsilon\}^{T}[\bar{Q}]\{\varepsilon\}\right) d x d y \\
& =\frac{1}{2} \int_{A}\left(\varepsilon_{L}+\varepsilon_{N L}\right)^{T}[\bar{Q}]\left(\varepsilon_{L}+\varepsilon_{N L}\right) d A .
\end{aligned}
$$

The Eq. (26) can be further modified as follows:

$$
\begin{aligned}
U_{s}= & \frac{1}{2} \int_{A}\left(\left\{\varepsilon_{L}\right\}^{T}\left[P_{1}\right]\left\{\varepsilon_{L}\right\}+\frac{1}{2}\left\{\varepsilon_{L}\right\}^{T}\left[P_{2}\right]\left\{\varepsilon_{N L}\right\}\right. \\
& +\frac{1}{2}\left\{\varepsilon_{N L}\right\}^{T}\left[P_{3}\right]\left\{\varepsilon_{L}\right\} \\
& \left.+\frac{1}{4}\left\{\varepsilon_{N L}\right\}^{T}\left[P_{4}\right]\left\{\varepsilon_{N L}\right\}\right) d A, \\
P_{1}= & \sum_{i=1}^{8} \int_{-h / 2}^{h / 2}\left[H_{L}\right]^{T}[\bar{Q}]\left[H_{L}\right] d z, \\
P_{2}= & \sum_{i=1}^{8} \int_{-h / 2}^{h / 2}\left[H_{L}\right]^{T}[\bar{Q}]\left[H_{N L}\right] d z, \\
P_{3}= & \sum_{i=1}^{8} \int_{-h / 2}^{h / 2}\left[H_{N L}\right]^{T}[\bar{Q}]\left[H_{L}\right] d z, \\
P_{4}= & \sum_{i=1}^{8} \int_{-h / 2}^{h / 2}\left[H_{N L}\right]^{T}[\bar{Q}]\left[H_{N L}\right] d z,
\end{aligned}
$$

where $\left[H_{L}\right]$ and $\left[H_{N L}\right]$ are the thickness matrices given in Appendix (Eq. (A.2)), and $\left[P_{1}\right],\left[P_{2}\right],\left[P_{3}\right]$ and $\left[P_{4}\right]$ are the modified reduced elastic stiffness matrices as expressed in Eq. (28).

The total strain energy $\left(U_{\text {total }}\right)$ can be expressed as follows:

$$
U_{\text {total }}=\left(U_{s}+U_{e f}\right)
$$

The elastic strain energy of the FGM plate $\left(U_{s}\right)$ is: 


$$
\begin{aligned}
U_{s}= & \frac{1}{2}\left(\{\delta\}^{t r}\left\{B_{L}\right\}^{t r}\left[P_{1}\right]\left\{B_{L}\right\}\{\delta\}\right. \\
& +\frac{1}{2}\{\delta\}^{t r}\left\{B_{L}\right\}^{t r}\left[P_{2}\right]\left\{B_{N L}\right\}\{\delta\} \\
& +\frac{1}{2}\{\delta\}^{\operatorname{tr}}\left\{B_{N L}\right\}^{\operatorname{tr}}\left[P_{3}\right]\left\{B_{L}\right\}\{\delta\} \\
& \left.+\frac{1}{4}\{\delta\}^{\operatorname{tr}}\left\{B_{N L}\right\}^{\operatorname{tr}}\left[P_{4}\right]\left\{B_{N L}\right\}\{\delta\}\right) .
\end{aligned}
$$

The strain energy due to elastic foundation $\left(U_{e f}\right)$ is:

$$
U_{e f}=\frac{1}{2} \int_{0}^{a} \int_{0}^{b}\left[k_{w} w^{2}+k_{s}\left(\left(\frac{\partial w}{\partial x}\right)^{2}+\left(\frac{\partial w}{\partial y}\right)^{2}\right)\right] d x d y
$$

where $k_{w}$ and $k_{s}$ are the Winkler and shear/Pasternak moduli.

\subsection{Kinetic energy}

The kinetic energy of an FGM plate is expressed as in the study of Cook et al. [33]:

$$
\begin{aligned}
T & =\frac{1}{2} \int_{-h / 2}^{h / 2} \rho\left[(\dot{u})^{2}+(\dot{v})^{2}+(\dot{w})^{2}\right] d A \\
& =\frac{1}{2}\{\dot{\delta}\}^{t r}[M]\{\dot{\delta}\} .
\end{aligned}
$$

The mass matrix for the FGM plate resting on the elastic foundation is presented as follows:

$$
[M]=\int_{0}^{a} \int_{0}^{b}[N]^{t r}[I][N] d x d y=\int_{-1}^{1} \int_{-1}^{1}[N]^{t r}[I][N] d \xi d \eta,
$$

where $[I]$ and $[N]$ are the inertia and shape function matrix, respectively, as shown in Appendix (Eq. (A.3)).

\subsection{Work done due to thermal load}

Due to thermal load as well as non-uniform temperature rise along the temperature-dependent material properties, thermal stress tends to undergo geometric distortion. Due to a change in geometry, thermal stress is developed with a significant effect on the vibration characteristics. To calculate the solution based on the current transformed state of the structure, the second Piola-Kirchhoff stress has been considered in the direct iterative method of Green Lagrange-type nonlinearity. In this respect, it is required to calculate the geometric matrix due to the deformed geometry of the structure caused by thermal stress.

The stress developed due to the thermal effect can be presented as follows:

$$
\left\{\begin{array}{l}
N \\
M \\
P
\end{array}\right\}=\left[\int_{-h / 2}^{h / 2}\left\{[\bar{Q}]\left\{\{\alpha(z, T)\}\left(1, z, z^{3}\right) \Delta T\right\}\right\} d z\right]
$$

where:

$$
\left\{\begin{array}{lll}
N & M & P
\end{array}\right\}^{t r}=\left[\left\{N^{T}\right\},\left\{M^{T}\right\},\left\{P^{T}\right\}\right]^{t r},
$$

are the in-plane thermal forces, moments, and higherorder terms, respectively.

The work done due to the resultant thermal force is the resultant work carried out by thermal force viz. $W_{T}$ expressed as in the study of Cook et al. [33]:

$$
\begin{aligned}
& W_{T}=\int_{-h / 2}^{h / 2}\left\{\varepsilon_{G}\right\}^{t r}[S]\left\{\varepsilon_{G}\right\} d A, \\
& \left\{\varepsilon_{G}\right\}=[H]\left[A_{g}\right][\aleph]=\left[B_{G}\right]\{\delta\} .
\end{aligned}
$$

Further, Eq. (34) can be rewritten as follows:

$$
W_{T}=\frac{1}{2} \int_{A}\left(\{\delta\}^{t r}\left[B_{G}\right]^{t r}[S]\left[B_{G}\right]\{\delta\}\right) d A,
$$

where $\left\{\varepsilon_{G}\right\}$ is the geometric strain vector, $\left[B_{G}\right]$ is the product form of a differential operator, and the corresponding matrices $[H],\left[A_{g}\right],[\aleph],[S]$ are described, as shown in Eqs. (A.4), (A.5), (A.6), and (A.7) in the Appendix. The elemental geometric stiffness matrix $\left[K_{G}\right]$ for geometric distortion due to thermal load can be expressed as follows:

$$
\begin{aligned}
{\left[K_{G}\right] } & =\int_{0}^{a} \int_{0}^{b}\left(\left[B_{G}\right]^{t r}[S]\left[B_{G}\right]\right) d x d y \\
& =\int_{-1}^{1} \int_{-1}^{1}\left(\left[B_{G}\right]^{t r}[S]\left[B_{G}\right]\right) d \xi d \eta .
\end{aligned}
$$

\section{The governing equation}

The governing equations are obtained using Hamilton's principle:

$$
\begin{aligned}
& \int_{0}^{t} L d t=0, \\
& L=\delta \Pi=\delta\left[T-\left(U_{s}+U_{f}+W_{\Delta T}\right)\right] .
\end{aligned}
$$

By substituting Eqs. (30), (31), (32), and (35) in Eq. (37), the final form of the governing equation for nonlinear vibration can be presented as follows:

$$
\begin{aligned}
{[M] } & \{\ddot{\delta}\}+\left(\left[K_{L}\right]-\left[K_{G}\right]+\frac{1}{2}\left[K_{N L 1}\right]+\frac{1}{3}\left[K_{N L 2}\right]\right)\{\delta\} \\
& =0 .
\end{aligned}
$$

The global stiffness matrix is composed of linear stiffness matrix $\left[K_{L}\right]$, global geometric stiffness matrix $\left[K_{G}\right]$, and nonlinear global coupled stiffness matrices $\left[K_{N L 1}\right]$ and $\left[K_{N L 2}\right]$ that linearly and quadratically depends on the displacement vector: 


$$
\begin{aligned}
& {\left[K_{L}\right]=\int_{-1}^{1} \int_{-1}^{1}\left(\left[B_{L}\right]^{t r}\left[P_{1}\right]\left[B_{L}\right]\right)|J| d \xi d \eta,} \\
& {\left[K_{N L 1}\right]=\frac{1}{2} \int_{-1}^{1} \int_{-1}^{1}\left(\left[B_{L}\right]^{t r}\left[P_{2}\right]\left[B_{N L}\right]\right.} \\
& \left.+\left[B_{N L}\right]^{t r}\left[P_{3}\right]\left[B_{L}\right]\right)|J| d \xi d \eta, \\
& {\left[K_{N L 2}\right]=\frac{1}{4} \int_{-1}^{1} \int_{-1}^{1}\left(\left[B_{N L}\right]^{t r}\left[P_{4}\right]\left[B_{N L}\right]\right)|J| d \xi d \eta} \\
& {\left[K_{G}\right]=\int_{-1}^{1} \int_{-1}^{1}\left(\left[B_{G}\right]^{t r}[S]\left[B_{G}\right]\right)|J| d \xi d \eta .}
\end{aligned}
$$

In terms of eigenvalue and eigenvector form, Eq. (38) can be written as follows:

$$
\left(\left(\left[K_{L}\right]-\left[K_{G}\right]+\left[K_{N L 1}\right]+\left[K_{N L 2}\right]\right)-\omega^{2}[M]\right) \Delta=0,
$$

where $\omega$ and $\Delta$ are the natural frequency and its corresponding eigenvector, respectively.

\section{Methodology}

Eq. (41) can be solved using the direct iteration method, and the step-wise procedure is stated below:

Step 1. Evaluate the elemental stiffness and mass matrices using general finite element procedures;
Step 2. Calculate the global stiffness and mass matrix by assembling the elemental matrices;

Step 3. Solve linear eigenvalue using the global stiffness and mass matrix:

$$
\left([K]-\omega^{2}[M]\right)\{\delta\}=\{0\},
$$

Extract the linear eigenvalue and its corresponding eigenvector using a standard extraction algorithm;

Step 4. Scale up the amplitude ratio $\left(W_{\max } / h\right)$ by the desired value and the ratio of maximum deflection of plate $W_{\max }$ to the thickness of plate $h$ and normalize the mode shape vector;

Step 5. Obtain the nonlinear stiffness matrices $\left[K_{N L 1}\right]$ and $\left[K_{N L 2}\right]$ using the scaled-up eigenvector (mode shape) by a numerical integration technique;

Step 6. Solve the nonlinear eigenvalue equation untill the relative convergence criterion is $0.1 \%$ :

$$
\frac{\left|\omega_{i}-\omega_{i-1}\right|}{\omega_{i}} \leq 0.1 \%
$$

where $i$ denotes the iteration number.

\section{Validation}

In order to validate the present method, the numerical results of $\mathrm{Si}_{3} \mathrm{~N}_{4} / \mathrm{SUS} 304$ FGM plate are compared with the published results of the given literature. Table 1 shows the comparison of natural frequency parameters of a square $\mathrm{Si}_{3} \mathrm{~N}_{4} / \mathrm{SUS} 304$ FGM plate of side $0.2 \mathrm{~m}$ and side-thickness ratio $a / h=8$ subjected to three different thermal conditions along ceramic surface $T_{c}=300 \mathrm{~K}$,

Table 1. Comparison of natural frequency parameters for $\mathrm{Si}_{3} \mathrm{~N}_{4} / \mathrm{SUS} 304$ square plate in thermal environment: $a=b=0.2 \mathrm{~m}$, and $h=0.025 \mathrm{~m}$ (TD: Temperature Dependent; TI: Temperature Independent).

\begin{tabular}{llccccc}
\hline \multirow{2}{*}{ Temperature } & \multicolumn{1}{c}{ Source } & \multicolumn{5}{c}{ Volume fraction index $(\boldsymbol{n})$} \\
\cline { 3 - 7 } & & Ceramic & $\boldsymbol{n}=\mathbf{0 . 5}$ & $\boldsymbol{n}=\mathbf{1}$ & $\boldsymbol{n}=\mathbf{2}$ & Metal \\
\hline \multirow{2}{*}{$T_{c}=T_{m}=300 \mathrm{~K}$} & Present & 12.5081 & 8.7169 & 7.6081 & 6.7374 & 5.4108 \\
& Huang and Shen [22] & 12.495 & 8.675 & 7.555 & 6.777 & 5.405 \\
& & & & & \\
$T_{c}=400 \mathrm{~K}$, & Present & 12.3429 & 8.5815 & 7.4810 & 6.6154 & 5.2908 \\
$T_{m}=300 \mathrm{~K}(\mathrm{TD})$ & Huang and Shen [22] & 12.397 & 8.615 & 7.474 & 6.693 & 5.311 \\
& & & & & & \\
$T_{c}=400 \mathrm{~K}$, & Present & 12.3781 & 8.6010 & 7.4953 & 6.6258 & 5.2946 \\
$T_{m}=300 \mathrm{~K}(\mathrm{TI})$ & Huang and Shen [22] & 12.382 & 8.641 & 7.514 & 6.728 & 5.335 \\
& & & & & & \\
$T_{c}=600 \mathrm{~K}$, & Present & 12.0487 & 8.3147 & 7.2199 & 6.3558 & 5.0149 \\
$T_{m}=300 \mathrm{~K}(\mathrm{TD})$ & Huang and Shen [22] & 11.984 & 8.269 & 7.171 & 6.398 & 4.971 \\
$T_{c}=600 \mathrm{~K}$, & Present & & & & & \\
$T_{m}=300 \mathrm{~K}(\mathrm{TI})$ & Huang and Shen [22] & 12.213 & 8.425 & 7.305 & 6.523 & 5.104 \\
\hline
\end{tabular}


$400 \mathrm{~K}$, and $600 \mathrm{~K}$. The reference temperature is $T_{0}=$ $T_{m}=300 \mathrm{~K}$. The calculated frequency parameter $(\omega)$ is compared with the results reported by Huang and Shen [22]. The comparison shows good agreement. The volume fraction index $n=0$ corresponds to ceramic and $n=8$ corresponds to metal.

Table 2 shows the comparison of the nondimensional natural frequency of simply supported square isotropic plate $(n=0)$ and values given by Baferani et al. [3]. Very good agreement can be observed for all boundary conditions. Table 3 presents the comparison of nonlinear frequency ratio of the simply supported FGM plate and the values given in Sundararajan et al. [21]. The volume fraction of the FGM plate $(n=1)$ and side-thickness ratio $a / h=10$. The comparison shows very good agreement. Hence, the present formulation can be trusted.

\section{Results and discussion}

A square $\mathrm{Si}_{3} \mathrm{~N}_{4} / \mathrm{SUS} 304$ FGM plate composed of silicon nitride (ceramic) and steel (metal) supported on the elastic foundation has been considered for the parametric study. The side of the plate is $1 \mathrm{~m}$ and thickness is

Table 2. Comparison of non-dimensional natural frequency, $\omega$, for homogeneous isotropic SSSS, SSSC, SCSC, and SSSF plates, $n=0$.

\begin{tabular}{|c|c|c|c|c|c|c|}
\hline \multicolumn{2}{|c|}{ Foundation parameters } & \multirow{2}{*}{ Method } & \multicolumn{4}{|c|}{ Boundary conditions } \\
\hline$K_{w}$ & $K_{s}$ & & SSSS & SSSC & SCSC & SSSF \\
\hline \multirow{6}{*}{0} & \multirow{2}{*}{0} & Present & 19.7350 & 23.6594 & 28.9950 & 11.6765 \\
\hline & & Baferani et al. [3] & 19.7374 & 23.6428 & 28.9441 & 11.6898 \\
\hline & \multirow{2}{*}{100} & Present & 48.5473 & 51.2529 & 54.6165 & 37.1015 \\
\hline & & Baferani et al. [3] & 48.6149 & 51.3175 & 54.6742 & 37.1519 \\
\hline & \multirow{2}{*}{1000} & Present & 140.1819 & 142.4385 & 144.8770 & 110.4241 \\
\hline & & Baferani et al. [3] & 141.8730 & 144.24 & 146.7191 & 111.7454 \\
\hline \multirow{6}{*}{100} & \multirow{2}{*}{0} & Present & 22.1254 & 25.6867 & 30.6717 & 15.3732 \\
\hline & & Baferani et al. [3] & 22.1261 & 25.6706 & 30.6229 & 15.3834 \\
\hline & \multirow{2}{*}{100} & Present & 49.5661 & 52.2199 & 55.5237 & 38.4263 \\
\hline & & Baferani et al. [3] & 49.6327 & 52.2827 & 55.5811 & 38.4742 \\
\hline & \multirow{2}{*}{1000} & Present & 140.5379 & 142.7889 & 145.2219 & 110.8759 \\
\hline & & Baferani et al. [3] & 142.2250 & 144.5466 & 147.0595 & 112.1920 \\
\hline \multirow{6}{*}{1000} & \multirow{2}{*}{0} & Present & 37.2744 & 39.4928 & 42.9024 & 33.7078 \\
\hline & & Baferani et al. [3] & 37.2763 & 39.4834 & 42.8686 & 33.7139 \\
\hline & \multirow{2}{*}{100} & Present & 57.9363 & 60.2224 & 63.1093 & 48.7487 \\
\hline & & Baferani et al.[3] & 57.9945 & 60.2781 & 63.1603 & 48.7878 \\
\hline & \multirow{2}{*}{1000} & Present & 143.7040 & 145.9058 & 148.2876 & 114.8621 \\
\hline & & Baferani et al. [3] & 145.3545 & 147.6268 & 150.0881 & 116.1336 \\
\hline
\end{tabular}

Table 3. Comparison study of the nonlinear frequency ratio of a simply supported FGM plate at ambient temperature: $a / b=1, a / h=10$, and $n=1$.

\begin{tabular}{|c|c|c|c|c|c|c|}
\hline \multirow[b]{2}{*}{$W_{\max } / \boldsymbol{h}$} & \multicolumn{2}{|c|}{$T_{c}=T_{m}=300 \mathrm{~K}$} & \multicolumn{2}{|c|}{$T_{c}=400 \mathrm{~K}, T_{m}=300 \mathrm{~K}$} & \multicolumn{2}{|c|}{$T_{c}=600 \mathrm{~K}, T_{m}=300 \mathrm{~K}$} \\
\hline & $\begin{array}{c}\text { Sundararajan } \\
\text { et al. }[21]\end{array}$ & Present & $\begin{array}{c}\text { Sundararajan } \\
\text { et al. }[21]\end{array}$ & Present & $\begin{array}{c}\text { Sundararajan } \\
\text { et al. }[21]\end{array}$ & Present \\
\hline 0.2 & 1.0063 & 1.0188 & 1.0076 & 1.0089 & 1.0107 & 1.0219 \\
\hline 0.4 & 1.0654 & 1.0751 & 1.0702 & 1.0348 & 1.0818 & 1.0872 \\
\hline 0.6 & 1.1707 & 1.1688 & 1.1802 & 1.1761 & 1.2037 & 1.1949 \\
\hline 0.8 & 1.3155 & 1.3057 & 1.3267 & 1.3245 & 1.3638 & 1.3365 \\
\hline 1.0 & 1.4789 & 1.4674 & 1.50 & 1.5493 & 1.5518 & 1.5578 \\
\hline
\end{tabular}


Table 4. Temperature-dependent material properties of elastic modulus, $E$ (GPa), Poisson's ratio, $v$, coefficient of thermal expansion, $\alpha(1 / K)$, density, $\rho\left(\mathrm{kg} / \mathrm{m}^{3}\right)$, and thermal conductivity, $k,(\mathrm{~W} / \mathrm{mK})$ of ceramic and metal.

\begin{tabular}{ccccccc}
\hline Material & $\boldsymbol{P}_{\mathbf{0}}$ & $\boldsymbol{P}_{-\mathbf{1}}$ & $\boldsymbol{P}_{\mathbf{1}}$ & $\boldsymbol{P}_{\mathbf{2}}$ & $\boldsymbol{P}_{\mathbf{3}}$ & $\boldsymbol{P}$ (at 300 K) \\
\hline $\mathrm{Si}_{3} \mathrm{~N}_{4}$ & & & & & & \\
$E$ & 348.43 & 0 & $-3.070 \times 10^{-13}$ & $2.160 \times 10^{-16}$ & $-8.946 \times 10^{-20}$ & 322.2715 \\
$\alpha$ & $5.8723 \times 10^{-6}$ & 0 & $9.095 \times 10^{-6}$ & 0 & 0 & $7.4746 \times 10^{-6}$ \\
$\rho$ & 2370 & 0 & 0 & 0 & 0 & 2370 \\
$k$ & 9.19 & 0 & 0 & 0 & 0 & 9.19 \\
& & & & & & 207.7877 \\
$\mathrm{SUS304}$ & 201.04 & 0 & $3.079 \times 10^{-13}$ & $-6.534 \times 10^{-16}$ & 0 & $15.321 \mathrm{e}-6$ \\
$E$ & $12.330 \mathrm{e}-6$ & 0 & $8.086 \mathrm{e}-6$ & 0 & 0 & 8166 \\
$\alpha$ & 8166 & 0 & 0 & 0 & 0 & 0 \\
\hline
\end{tabular}

$0.05 \mathrm{~m}$. The Poisson's ratio, $v$, is assumed to be 0.28 . The two-parameter (Pasternak) elastic foundation has been considered. The material properties of ceramic and metal are shown in Table 4. The Poisson's ratio is taken as $v=0.28$.

Non-dimensional frequency $(\bar{\omega})$ as given in Dehghan and Baradaran [14] is:

$$
\bar{\omega}=\frac{\omega b^{2}}{\pi^{2}} \sqrt{\frac{\rho h}{D}}, \quad D=\frac{E h^{3}}{12\left(1-v^{2}\right)} .
$$

Non-dimensional elastic coefficients of Winkler and Pasternak are:

$$
K_{w}=\frac{k_{w} a^{4}}{D}, \quad K_{s}=\frac{k_{s} a^{2}}{D} .
$$

\subsection{Effect of volume fraction index $(n)$}

Figure 4 shows the effect of volume fraction index $(n)$ on the frequency parameter of an FGM plate with

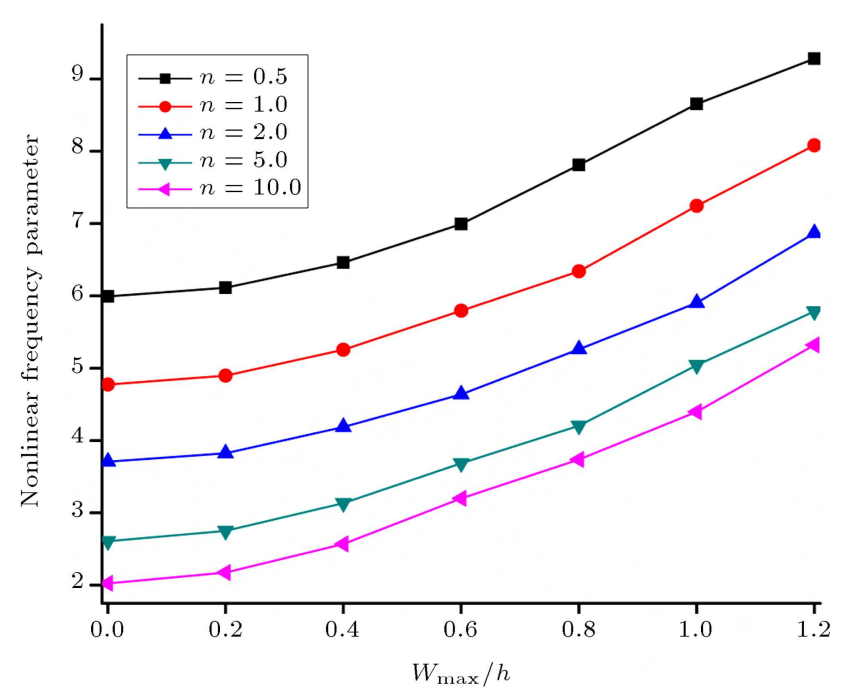

Figure 4. Variation of nonlinear frequency parameter for different volume fraction indexes $(n)$. a side-thickness ratio $(a / h=40)$, elastic foundation modulus coefficient $K_{w}=K_{s}=100$, and the temperature along the ceramic side $\left(T_{c}=400 \mathrm{~K}\right)$ with a change in amplitude ratio. The linear and nonlinear frequencies decrease with an increase in the volume fraction index. With an increase in the value of volume fraction index, the ceramic content decreases, thereby decreasing the stiffness. Hence, the frequency parameter decreases.

\subsection{Effect of aspect ratio $(a / b)$ and side-thickness ratio $(a / h)$}

Figure 5(a) shows the effect of aspect ratio on the nonlinear frequency parameter of the FGM plate with volume fraction index $n=0.5,1$, and 2 , side-thickness ratio $a / h=20$, the elastic foundation modulus coefficient $K_{w}=K_{s}=100$, and the temperature in ceramic side $T_{c}=400 \mathrm{~K}$ with a change in amplitude ratio. The amplitude ratio $\left(W_{\max } / h\right)$ presents the degree of nonlinearity. $W_{\max }$ presents the maximum transverse displacement with $h$, the thickness of the element. When $W_{\max } / h=0$, it provides a complete linear condition and, with a simultaneous increase in amplitude, the nonlinearity increases. Hence, it is observed that, with an increase in aspect ratio, both the linear and nonlinear frequency parameters increase. Figure 5(b) shows the effect of side-thickness ratio $(a / h)$ on the frequency parameter of the FGM plate $\left(a / h=30, K_{w}=10, K_{s}=10\right.$, and $\left.\Delta T=100 \mathrm{~K}\right)$ with an increase in amplitude ratio. Both the linear and nonlinear frequency parameters decrease with an increase in the side-thickness ratio.

\subsection{Effect of Winkler modulus $\left(K_{w}\right)$ and Pasternak/shear modulus $\left(K_{s}\right)$}

Figure 6 presents the influence of foundation modulus $\left(K_{w}, K_{s}\right)$ on the nonlinear frequency parameter of $\mathrm{Si}_{3} \mathrm{~N}_{4} /$ SUS304 FGM plate $(n=0.5,1$ and $2, a / h=40$, 


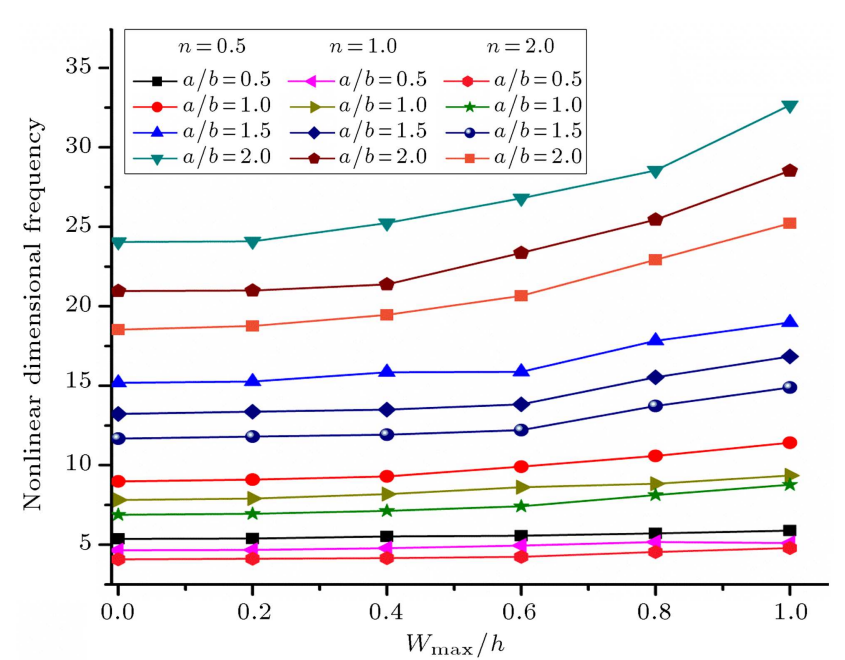

(a)

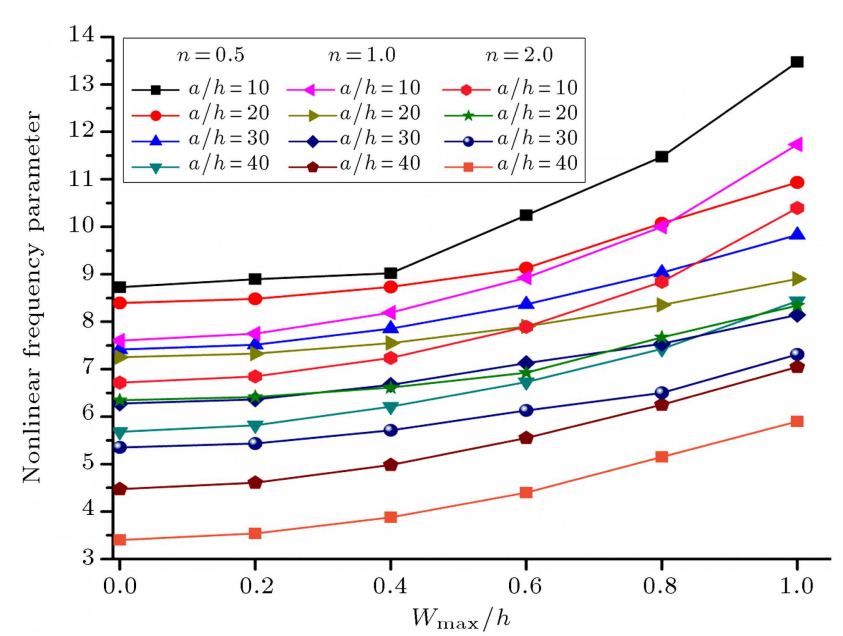

(b)

Figure 5. (a) Variation of nonlinear frequency parameter with varying aspect ratios. (b) Variation of nonlinear frequency parameter with varying side-thickness ratio.

$\Delta T=100 \mathrm{~K}$ ) with a change in amplitude ratio. In Figure 6(a) the frequency parameter increases with an increase in the values of $W_{\max } / h$ and $K_{w}$ by keeping the shear modulus coefficient as constant, $K_{s}=10$. In Figure 6(b) the frequency parameter increases with an increase in the values of $K_{s}$ and $W_{\max } / h$ by keeping the Winkler modulus coefficient as constant, $K_{w}=10$. The frequency parameter for an FGM plate is higher if the plate rests on the elastic foundation. A small change in frequency parameter is noticed with the rise in Winkler modulus coefficient, whereas a significant change is noticed when the plate is supported on Pasternak/shear elastic foundation.

Figure 7 shows the effect of the elastic foundation modulus with Winkler modulus coefficient $\left(K_{w}\right)$ and shear layer modulus coefficient $\left(K_{s}\right)$ on the frequency parameter of the FGM plate with volume fraction index $(n=1)$, the side-thickness ratio $(a / h=30,40)$, and temperature rise $(\Delta T=100 \mathrm{~K})$. The reference

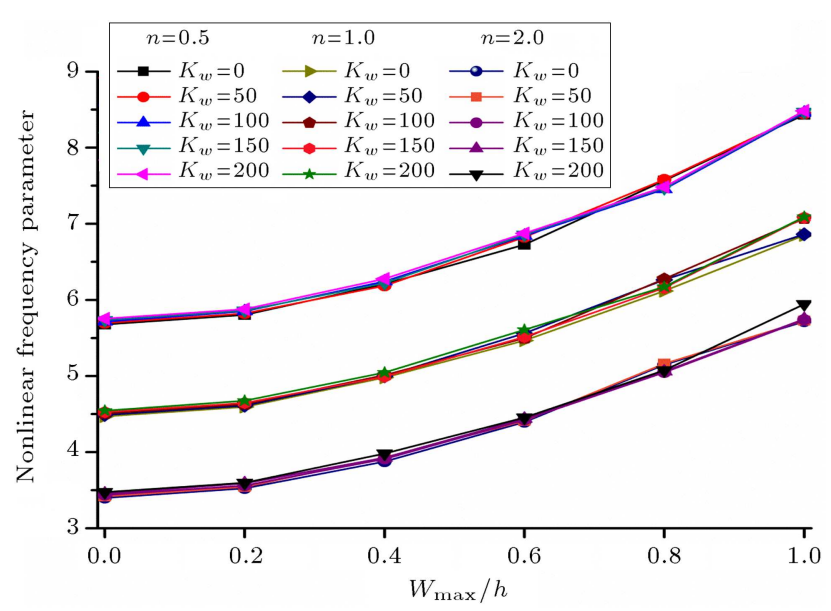

(a)

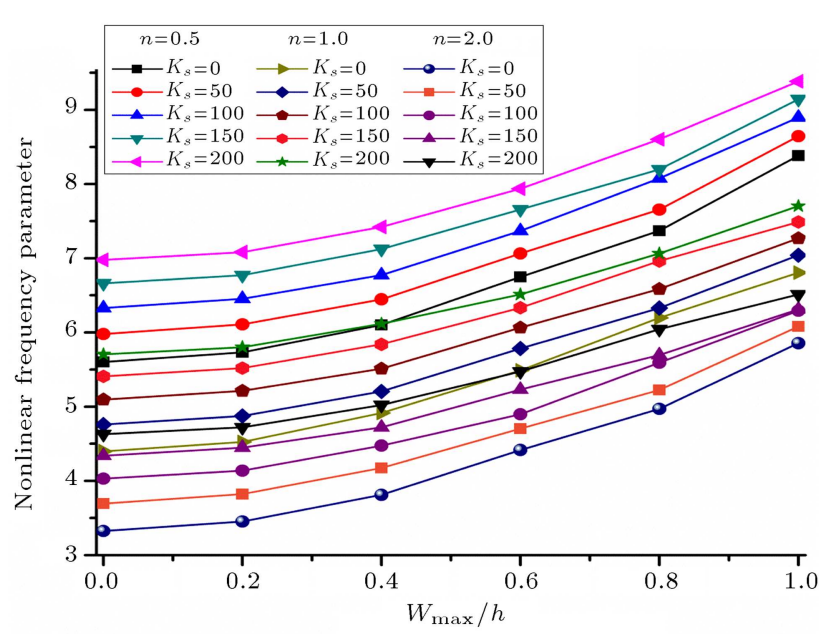

(b)

Figure 6. (a) Variation of the nonlinear frequency parameter for different Winkler modulus coefficients $\left(K_{w}\right)$ with changes in the amplitude ratio. (b) Variation of nonlinear frequency parameter for different shear modulus coefficient $\left(K_{s}\right)$ with change in amplitude ratio.

temperature is considered as $300 \mathrm{~K}$ along the metal side $\left(T_{m}=300 \mathrm{~K}\right)$. The plate supported on the elastic foundation has a higher frequency parameter than the plate without foundation. The shear layer modulus has a more significant effect on the fundamental frequency parameter than the Winkler modulus. The linear and nonlinear frequency parameters increase with an increase in Winkler modulus and, also, increases with an increase in shear layer modulus.

\subsection{Effect of change in temperature}

Figure 8 shows the variation of nonlinear frequency parameter with a change in nonlinear temperature along the ceramic side of the FGM plate with side-thickness ratio $(a / h=30)$ for different compositions $(n=0.5,1$ and 2). The two-parameter elastic foundation modulus consists of Winkler modulus coefficient $K_{w}=50$ and shear modulus coefficient $K_{s}=50$. The linear and nonlinear frequency parameters decrease with an increase 


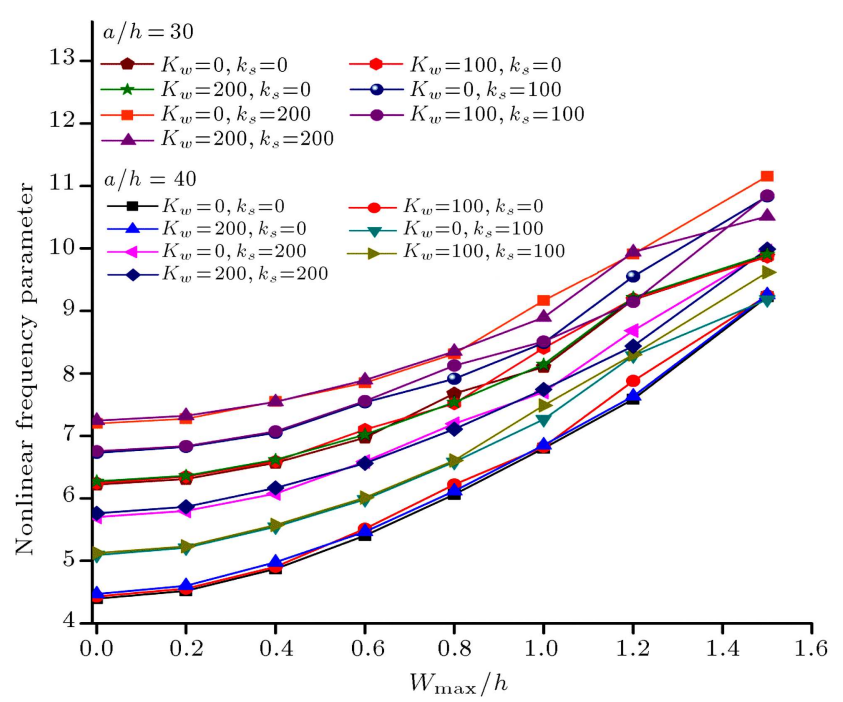

Figure 7. Nonlinear frequency parameter versus amplitude ratio with the varying elastic foundation modulus, $K_{w}, K_{s}$, at different side-thickness ratios.

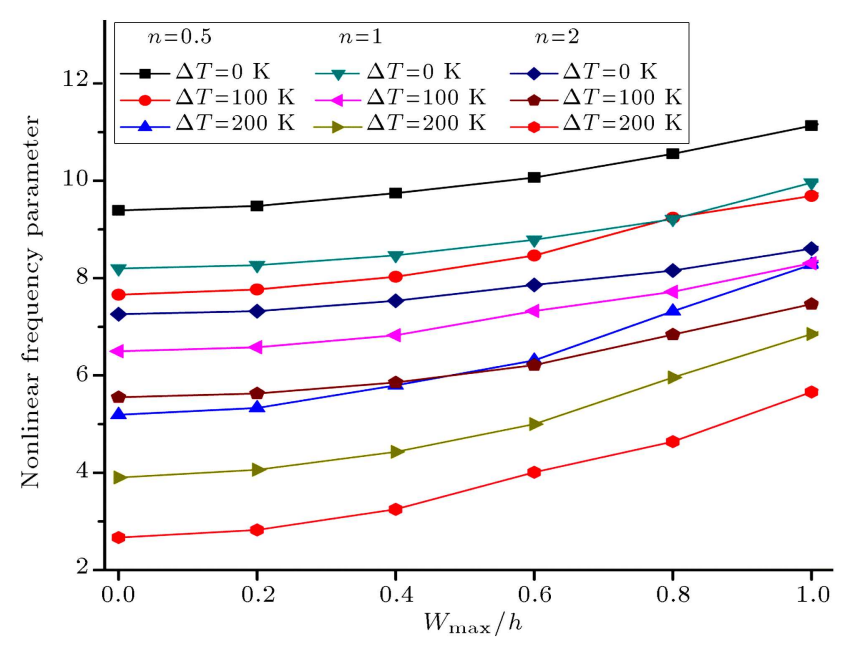

Figure 8. Nonlinear frequency parameter versus amplitude ratio with varying temperature rises.

in temperature rise $(\Delta T)$. At higher temperatures, the Young's modulus of the plate weakens and, thus, reduces the corresponding frequency and degrades the strength of the material, as shown in Figure 9.

\subsection{Effect of boundary conditions}

Figure 10 shows the effect of varying boundary conditions on frequency parameter for the FGM plate with different compositions $n=0.5,1,2$, side-thickness ratio $a / h=20$, elastic foundation modulus coefficient $K_{w}=K_{s}=100$, and the temperature at ceramic side $T_{c}=400 \mathrm{~K}$ with a change in amplitude ratio. The FGM plate with all sides clamped has higher linear and nonlinear frequency parameters followed by SCSC (simply supported-clamped-simply supportedclamped) and SSSS (all sides are simply supported).

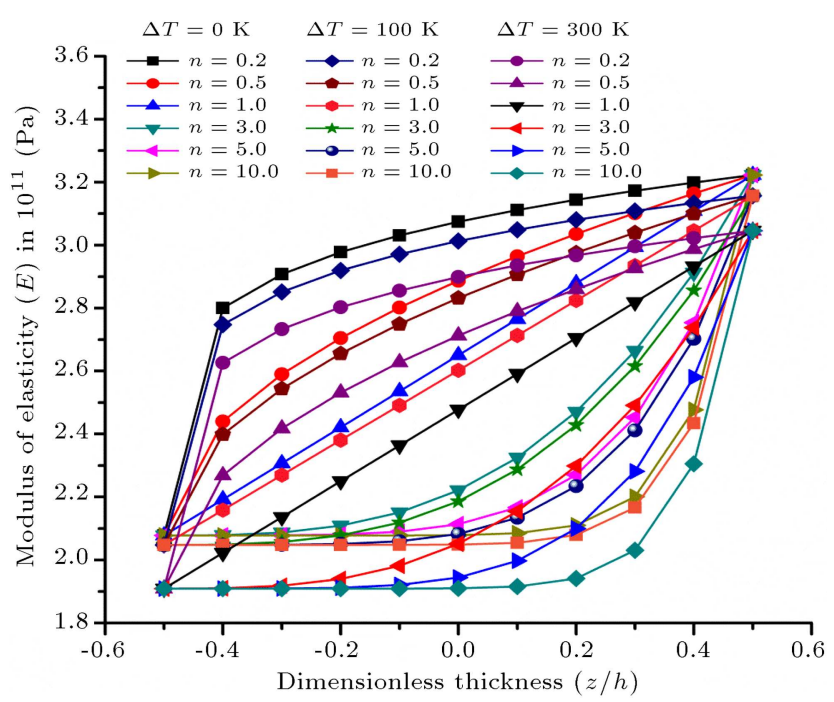

Figure 9. Variation of modulus of elasticity with changes in temperature increment and volume fraction index with varying dimensionless thicknesses.

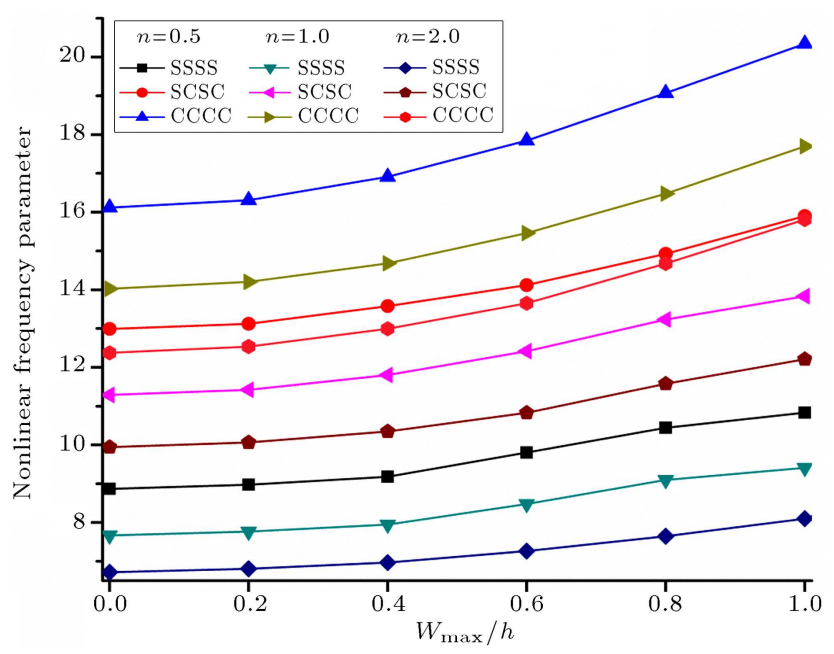

Figure 10. Variation of nonlinear frequency parameter with changes in boundary conditions.

The frequency increases with an increase in the number of clamped sides.

\section{Conclusion}

In this study, a numerical method was employed to obtain the nonlinear frequency parameters using modified HSDT with $C^{0}$ continuity. By considering Green-Lagrange nonlinearity, a general case was developed that includes all the nonlinear terms and predicts the original flexure of the plate. The nonlinear analysis showed hardening type nonlinear behavior that depends on the level of amplitude. The number of iterations involved to obtain the convergence of solution increases with increases in the amplitude ratio.

It was found that the intermediate material property did not necessarily give intermediate nonlinear 
frequency. The conclusions drawn from the outcomes are:

a. The shear layer modulus coefficient has a greater effect on the fundamental frequency parameter than Winkler modulus coefficient does. The linear and nonlinear frequency parameters of the FGM plate increased with an increase in Winkler coefficient and Pasternak/shear coefficient;

b. The linear and nonlinear frequency parameters of the FGM plate resting on the elastic foundation increase with an increase in the aspect ratio and decrease with an increase in side-thickness ratio;

c. The nonlinear fundamental frequency of the FGM plate resting on elastic foundation decreases with an increase in volume fraction index and in temperature along the ceramic surface;

d. The nonlinear fundamental frequency increases with an increase in the number of clamped sides and decreases with an increase in the number of simply supported sides.

\section{References}

1. Akhavan, H., Hashemi, S.H., Taher, H.R.D., Alibeigloo, A., and Vahabi, S. "Exact solutions for rectangular Mindlin plates under in-plane loads resting on Pasternak elastic foundation. Part I: Buckling analysis", Comput. Mater. Sci., 44, pp. 968-978 (2009).

2. Akhavan, H., Hashemi, S.H., Taher, H.R.D., Alibeigloo, A., and Vahabi, S. "Exact solutions for rectangular Mindlin plates under in-plane loads resting on Pasternak elastic foundation. Part II: Frequency analysis", Comput. Mater. Sci., 44, pp. 951-961 (2009).

3. Baferani, A.H., Saidi, A.R., and Ehteshami, H. "Accurate solution for free vibration analysis of functionally graded thick rectangular plates resting on elastic foundation", Compos. Struct., 93, pp. 1842-1853 (2011).

4. Bodaghi, M. and Saidi, A.R. "Stability analysis of functionally graded rectangular plates under nonlinearly varying in-plane loading resting on elastic foundation", Arch. Appl. Mech., 81, pp. 765-780 (2011).

5. Chien, R.-D. and Chen, C.-S. "Nonlinear vibration of laminated plates on a nonlinear elastic foundation", Compos. Struct., 70, pp. 90-99 (2005).

6. Duc, N.D., Bich, D.H., and Cong, P.H. "Nonlinear thermal dynamic response of shear deformable FGM plates on elastic foundations", J. Therm. Stress., 39, pp. 278-297 (2016).

7. Gajendar, N. "Large amplitude vibration of plates on elastic foundations", Int. J. Non-Linear Mech., 2, pp. 163-172 (1967).
8. Kiani, Y., Shakeri, M., and Eslami, M.R. "Thermoelastic free vibration and dynamic behaviour of an FGM doubly curved panel via the analytical hybrid LaplaceFourier transformation", Acta Mech., 223, pp. 11991218 (2012).

9. Kiani, Y., Akbarzadeh, A.H., Chen, Z.T., and Eslami, M.R. "Static and dynamic analysis of an FGM doubly curved panel resting on the Pasternak-type elastic foundation", Compos. Struct., 94, pp. 24742484 (2012).

10. Shen, H., Chen, X., Licheng, G., Wu, L., and Huang, X.-L. "Nonlinear vibration of FGM doubly curved panel resting on elastic foundations in thermal environments", Aerosp. Sci. Technol., 47, pp. 434-446 (2015).

11. Shen, H.S. and Wang, Z.X. "Nonlinear vibration of hybrid laminated plates resting on elastic foundations in thermal environments", Appl. Math. Model., 36, pp. 6275-6290 (2012).

12. Shen, H.S. and Wang, H. "Nonlinear vibration of shear deformable FGM cylindrical panels resting on elastic foundations in thermal environments", Compos. Part B Eng., 60, pp. 167-177 (2014).

13. Huang, Z.Y., Lu, C.F., and Chen, W.Q. "Benchmark solutions for functionally graded thick plates resting on Winkler-Pasternak elastic foundations", Compos. Struct., 85, pp. 95-104 (2008).

14. Dehghan, M. and Baradaran, G.H. "Buckling and free vibration analysis of thick rectangular plates resting on elastic foundation using mixed finite element and differential quadrature method", Appl. Math. Comput., 218, pp. 2772-2784 (2011).

15. Qin, Q.H. and Diao, S. "Nonlinear analysis of thick plates on an elastic foundation by HT FE with pextension capabilities", Int. J. Solid Struct., 33, pp. 4583-4604 (1996).

16. Duc, N.D. and Cong, P.H. "Nonlinear postbuckling of symmetric S-FGM plates resting on elastic foundations using higher order shear deformation plate theory in thermal environments", Compos. Struct., 100, pp. 566574 (2013).

17. Fallah, A., Aghdam, M.M., and Kargarnovin, M.H. "Free vibration analysis of moderately thick functionally graded plates on elastic foundation using the extended Kantorovich method", Arch. Appl. Mech., 83, pp. 177-191 (2013).

18. Fallah, A. and Aghdam, M.M. "Nonlinear free vibration and post-buckling analysis of functionally graded beams on nonlinear elastic foundation", Eur. J. Mech. A/Solids., 30, pp. 571-583 (2011).

19. Taczała, M., Buczkowski, R., and Kleiber, M. "Nonlinear free vibration of pre- and post-buckled FGM plates on two-parameter foundation in the thermal environment", Compos. Struct., 137, pp. 85-92 (2016).

20. Yang, Z., Yuan-yuan, G., and Fangin, B. "Solution for a rectangular plate on elastic foundation with free edges using reciprocal theorem method", Math. Eterna., 2, pp. 335-343 (2012). 
21. Sundararajan, N., Prakash, T., and Ganapathi, M. "Nonlinear free flexural vibrations of functionally graded rectangular and skew plates under thermal environments", Finite Elem. Anal. Des., 42, pp. 152168 (2005).

22. Huang, X.-L. and Shen, H.-S. "Nonlinear vibration and dynamic response of functionally graded plates in thermal environments", Int. J. Solids Struct., 41, pp. 2403-2427 (2004).

23. Civalek, Ö. "Nonlinear analysis of thin rectangular plates on Winkler-Pasternak elastic foundations by DSC-HDQ methods", Appl. Math. Model., 31, pp. 606624 (2007).

24. Qin, Q.H. "Nonlinear analysis of reissner plates on an elastic foundation by the bem", Int. J. Solids Struct., 30, pp. 3101-3111 (1993).

25. Singha, M.K. and Daripa, R. "Nonlinear vibration and dynamic stability analysis of composite plates", J. Sound Vib., 328, pp. 541-554 (2009).

26. Thi, V.T.A. and Duc, N.D. "Nonlinear response of a shear deformable S- FGM shallow spherical shell with ceramic-metal- ceramic layers resting on an elastic foundation in a thermal environment", Mech. Adv. Mater. Struct., 23, pp. 926-934 (2016).

27. Tornabene, F., Fantuzzi, N., Viola, E., and Reddy, J.N. "Winkler-Pasternak foundation effect on the static and dynamic analyses of laminated doubly-curved and degenerate shells and panels", Compos. Part B Eng., 57, pp. 269-296 (2014).

28. Tornabene, F., Viola, E., and Fantuzzi, N. "General higher-order equivalent single layer theory for free vibrations of doubly-curved laminated composite shells and panels", Compos. Struct., 104, pp. 94-117 (2013).

29. Szekrenyes, A. "Nonsingular crack modelling in orthotropic plates by four equivalent single layers", Eur. J. Mech. - A/Solids., 55, pp. 73-99 (2016a).

30. Szekrenyes, A. "Semi-layerwise analysis of laminated plates with nonsingular delamination-The theorem of autocontinuity", Appl. Math. Model., 40(2), pp. 13441371 (2016b).

31. Touloukin, Y.S., Thermophysical Properties of High Temperature Solid Materials, MacMillan, New York (1967).

32. Petyt, M., Introduction to Finite Element Vibration Analysis, Cambridge University Press, 2nd Ed. (2010).

33. Cook, R.D., Malkus, D.S., Plesha, M.E., and Witt, R.J., Concepts and Applications of Finite Element Analysis, Fourth Edn., John Wiley \& Sons (Asia), Pvt. Ltd. (2002).

\section{Appendix}

$$
c_{1}=\frac{4}{3 h^{2}}, \quad \beta_{x}=\frac{\partial w_{0}}{\partial x}, \quad \beta_{y}=\frac{\partial w_{0}}{\partial y} .
$$

Strain terms:

$$
\begin{aligned}
\left\{\varepsilon_{L}\right\}=\left\{\begin{array}{l}
\varepsilon_{1}^{0} \\
\varepsilon_{2}^{0} \\
\varepsilon_{6}^{0} \\
\varepsilon_{5}^{0} \\
\varepsilon_{4}^{0}
\end{array}\right\}+z\left\{\begin{array}{l}
\kappa_{1}^{1} \\
\kappa_{2}^{1} \\
\kappa_{6}^{1} \\
\kappa_{5}^{1} \\
\kappa_{4}^{1}
\end{array}\right\}+z^{2}\left\{\begin{array}{l}
\kappa_{1}^{2} \\
\kappa_{2}^{2} \\
\kappa_{6}^{2} \\
\kappa_{5}^{2} \\
\kappa_{4}^{2}
\end{array}\right\}+z^{3}\left\{\begin{array}{l}
\kappa_{1}^{3} \\
\kappa_{2}^{3} \\
\kappa_{6}^{3} \\
\kappa_{5}^{3} \\
\kappa_{4}^{3}
\end{array}\right\}, \\
\left\{\varepsilon_{N L}\right\}= \\
+\frac{1}{2}\left\{\begin{array}{l}
\varepsilon_{1}^{n l 0} \\
\varepsilon_{2}^{n l 0} \\
\varepsilon_{6}^{n l 0} \\
\varepsilon_{5}^{n l 0} \\
\varepsilon_{4}^{n l 0}
\end{array}\right\}+\frac{z}{2}\left\{\begin{array}{l}
\kappa_{1}^{n l 1} \\
\kappa_{2}^{n l 1} \\
\kappa_{6}^{n l 1} \\
\kappa_{5}^{n l 1} \\
\kappa_{4}^{n l 1}
\end{array}\right\}+\frac{z^{2}}{2}\left\{\begin{array}{l}
\kappa_{1}^{n l 2} \\
\kappa_{2}^{n l 2} \\
\kappa_{6}^{n l 2} \\
\kappa_{5}^{n l 2} \\
\kappa_{4}^{n l 2}
\end{array}\right\} \\
+\frac{z^{3}}{2}\left\{\begin{array}{l}
\kappa_{1}^{n l 3} \\
\kappa_{2}^{n l 3} \\
\kappa_{6}^{n l 3} \\
\kappa_{5}^{n l 3} \\
\kappa_{4}^{n l 3}
\end{array}\right\}+\frac{z^{4}}{2}\left\{\begin{array}{l}
\kappa_{1}^{n l 4} \\
\kappa_{2}^{n l 4} \\
\kappa_{6}^{n l 4} \\
\kappa_{5}^{n l 4} \\
\kappa_{4}^{n l 4}
\end{array}\right\} \\
+\left\{\begin{array}{l}
\kappa_{1}^{n l 5} \\
\kappa_{2}^{n l 5} \\
\kappa_{6}^{n l 5} \\
\kappa_{5}^{n l 5} \\
\kappa_{4}^{n l 5}
\end{array}\right\}+\frac{z^{6}}{2}\left\{\begin{array}{l}
\kappa_{1}^{n l 6} \\
\kappa_{2}^{n l 6} \\
\kappa_{6}^{n l 6} \\
\kappa_{5}^{n l 6} \\
\kappa_{4}^{n l 6}
\end{array}\right\} .
\end{aligned}
$$

Linear strain terms:

$$
\left\{\begin{array}{l}
\varepsilon_{1}^{0} \\
\varepsilon_{2}^{0} \\
\varepsilon_{6}^{0} \\
\varepsilon_{5}^{0} \\
\varepsilon_{4}^{0}
\end{array}\right\}=\left\{\begin{array}{c}
\frac{\partial u_{0}}{\partial x} \\
\frac{\partial v_{0}}{\partial y} \\
\frac{\partial u_{0}}{\partial y}+\frac{\partial v_{0}}{\partial x} \\
\theta_{y}+\frac{\partial w_{0}}{\partial x} \\
-\theta_{x}+\frac{\partial w_{0}}{\partial y}
\end{array}\right\}
$$$$
\left\{\begin{array}{c}
\kappa_{1}^{1} \\
\kappa_{2}^{1} \\
\kappa_{6}^{1} \\
\kappa_{5}^{1} \\
\kappa_{4}^{1}
\end{array}\right\}=\left\{\begin{array}{c}
\frac{\partial \theta_{y}}{\partial x} \\
-\frac{\partial \theta_{x}}{\partial y} \\
-\frac{\partial \theta_{x}}{\partial x}+\frac{\partial \theta_{y}}{\partial y} \\
0 \\
0
\end{array}\right\},\left\{\begin{array}{c}
\kappa_{1}^{2} \\
\kappa_{2}^{2} \\
\kappa_{6}^{2} \\
\kappa_{5}^{2} \\
\kappa_{4}^{2}
\end{array}\right\}=c_{2}\left\{\begin{array}{c}
0 \\
0 \\
0 \\
\theta_{y}+\beta_{x} \\
-\theta_{x}+\beta_{y}
\end{array}\right\}
$$

$$
\left\{\begin{array}{c}
\kappa_{1}^{3} \\
\kappa_{2}^{3} \\
\kappa_{6}^{3} \\
\kappa_{5}^{3} \\
\kappa_{4}^{3}
\end{array}\right\}=c_{1}\left\{\begin{array}{c}
-\frac{\partial \theta_{y}}{\partial x}-\frac{\partial \beta_{x}}{\partial x} \\
\frac{\partial \theta_{x}}{\partial y}-\frac{\partial \beta_{y}}{\partial y} \\
-\frac{\partial \theta_{y}}{\partial y}+\frac{\partial \theta_{x}}{\partial x}-\frac{\partial \beta_{x}}{\partial y}-\frac{\partial \beta_{y}}{\partial x} \\
0 \\
0
\end{array}\right\}
$$


$c_{2}=3 c_{1}$.

Non-linear strain terms:

$$
\begin{aligned}
& \varepsilon_{1}^{n l 0}=\left[\left(u_{0, x}\right)^{2}+\left(v_{0, x}\right)^{2}+\left(w_{0, x}\right)^{2}\right], \\
& \varepsilon_{2}^{n l 0}=\left[\left(u_{0, y}\right)^{2}+\left(v_{0, y}\right)^{2}+\left(w_{0, y}\right)^{2}\right], \\
& \varepsilon_{6}^{n l 0}=\left[2 u_{0, x} u_{0, y}+2 v_{0, x} v_{0, y}+2 w_{0, x} w_{0, y}\right], \\
& \varepsilon_{5}^{n l 0}=\left[2 \theta_{y} u_{0, x}-2 \theta_{x} v_{0, x}\right] \text {, } \\
& \varepsilon_{4}^{n l 0}=\left[2 \theta_{y} u_{0, y}-2 \theta_{x} v_{0, y}\right] \text {, } \\
& \kappa_{1}^{n l 1}=\left[2 u_{0, x} \theta_{y, x}-2 v_{0, x} \theta_{x, x}\right], \\
& \kappa_{2}^{n l 1}=\left[2 u_{0, y} \theta_{y, y}-2 v_{0, y} \theta_{x, y}\right], \\
& \kappa_{6}^{n l 1}=\left[2 u_{0, x} \theta_{y, y}+2 u_{0, y} \theta_{y, x}-2 v_{0, x} \theta_{x, y}-2 v_{0, y} \theta_{x, x}\right], \\
& \kappa_{5}^{n l 1}=\left[2 \theta_{y, x} \theta_{y}+2 \theta_{x, x} \theta_{x}\right], \\
& \kappa_{4}^{n l 1}=\left[2 \theta_{y, y} \theta_{y}+2 \theta_{x, y} \theta_{x}\right] \text {, } \\
& \kappa_{1}^{n l 2}=\left[\left(\theta_{y, x}\right)^{2}+\left(\theta_{x, x}\right)^{2}\right] \text {, } \\
& \kappa_{2}^{n l 2}=\left[\left(\theta_{y, y}\right)^{2}+\left(\theta_{x, y}\right)^{2}\right] \text {, } \\
& \kappa_{6}^{n l 2}=\left[2 \theta_{y, x} \theta_{y, y}+2 \theta_{x, x} \theta_{x, y}\right], \\
& \kappa_{5}^{n l 2}=\left[-6 c_{1} \theta_{y} u_{0, x}-6 c_{1} \beta_{x} u_{0, x}+6 c_{1} \theta_{x} v_{0, x}\right. \\
& \left.-6 c_{1} \beta_{y} v_{0, x}\right] \\
& \kappa_{4}^{n l 2}=\left[-6 c_{1} \theta_{y} u_{0, y}-6 c_{1} \beta_{x} u_{0, y}+6 c_{1} \theta_{x} v_{0, y}\right. \\
& \left.-6 c_{1} \beta_{y} v_{0, y}\right] \\
& \kappa_{1}^{n l 3}=\left[-2 c_{1} u_{0, x} \theta_{y, x}-2 c_{1} u_{0, x} \beta_{x, x}+2 c_{1} v_{0, x} \theta_{x, x}\right. \\
& \left.-2 c_{1} v_{0, x} \beta_{y, x}\right] \\
& \kappa_{2}^{n l 3}=\left[-2 c_{1} u_{0, y} \theta_{y, y}-2 c_{1} u_{0, y} \beta_{x, y}+2 c_{1} v_{0, y} \theta_{x, y}\right. \\
& \left.-2 c_{1} v_{0, y} \beta_{y, y}\right] \\
& \kappa_{6}^{n l 3}=\left[-2 c_{1} u_{0, x} \theta_{y, y}-2 c_{1} u_{0, x} \beta_{x, y}-2 c_{1} u_{0, y} \theta_{y, x}\right. \\
& -2 c_{1} u_{0, y} \beta_{x, x}+2 c_{1} v_{0, x} \theta_{x, y}-2 c_{1} v_{0, x} \beta_{y, y} \\
& \left.+2 c_{1} v_{0, y} \theta_{x, x}-2 c_{1} v_{0, y} \beta_{y, x}\right], \\
& \kappa_{5}^{n l 3}=\left[-8 c_{1} \theta_{y, x} \theta_{y}-8 c_{1} \theta_{x, x} \theta_{x}-2 c_{1} \beta_{x, x} \theta_{y}\right. \\
& \left.+2 c_{1} \beta_{y, x} \theta_{x}-6 c_{1} \theta_{y, x} \beta_{x}-6 c_{1} \theta_{x, x} \beta_{y}\right], \\
& \kappa_{4}^{n l 3}=\left[-8 c_{1} \theta_{y, y} \theta_{y}-8 c_{1} \theta_{x, y} \theta_{x}-2 c_{1} \beta_{x, y} \theta_{y}\right. \\
& \left.+2 c_{1} \beta_{y, y} \theta_{x}-6 c_{1} \theta_{y, y} \beta_{x}+6 c_{1} \theta_{x, y} \beta_{y}\right],
\end{aligned}
$$

$$
\begin{aligned}
& \kappa_{1}^{n l 4}=\left[-2 c_{1}\left(\theta_{y, x}\right)^{2}-2 c_{1}\left(\theta_{x, x}\right)^{2}-2 c_{1} \theta_{y, x} \beta_{x, x}\right. \\
& \left.+2 c_{1} \theta_{x, x} \beta_{y, x}\right] \\
& \kappa_{2}^{n l 4}=\left[-2 c_{1}\left(\theta_{y, y}\right)^{2}-2 c_{1}\left(\theta_{x, y}\right)^{2}-2 c_{1} \theta_{y, y} \beta_{x, y}\right. \\
& \left.+2 c_{1} \theta_{x, y} \beta_{y, y}\right] \\
& \kappa_{6}^{n l 4}=\left[-4 c_{1} \theta_{y, y} \theta_{y, x}-2 c_{1} \theta_{y, y} \beta_{x, x}-4 \theta_{x, x} \theta_{x, y}\right. \\
& \left.+2 c_{1} \theta_{x, x} \beta_{y, y}-2 c_{1} \beta_{x, y} \theta_{y, x}+2 c_{1} \theta_{x, y} \beta_{y, x}\right], \\
& \kappa_{5}^{n l 4}=0, \quad \kappa_{4}^{n l 4}=0, \quad \kappa_{1}^{n l 5}=0, \\
& \kappa_{2}^{n l 5}=0, \quad \kappa_{6}^{n l 5}=0, \\
& \kappa_{5}^{n l 5}=\left[6 c_{1}^{2} \theta_{x, x} \theta_{x}-6 c_{1}^{2} \beta_{y, x} \theta_{x}-6 c_{1}^{2} \theta_{x, x} \beta_{y}\right. \\
& +6 c_{1}^{2} \beta_{y, x} \beta_{y}+6 c_{1}^{2} \theta_{y, x} \theta_{y}+6 c_{1}^{2} \beta_{x, x} \theta_{y} \\
& \left.+6 c_{1}^{2} \theta_{y, x} \beta_{x}+6 c_{1}^{2} \beta_{x, x} \beta_{x}\right], \\
& \kappa_{4}^{n l 5}=\left[6 c_{1}^{2} \theta_{y, y} \theta_{y}+6 c_{1}^{2} \beta_{x, y} \theta_{y}+6 c_{1}^{2} \theta_{y, y} \beta_{x}\right. \\
& +6 c_{1}^{2} \beta_{x, y} \beta_{x}+6 c_{1}^{2} \theta_{x, y} \theta_{x}-6 c_{1}^{2} \beta_{y, y} \theta_{x} \\
& \left.-6 c_{1}^{2} \theta_{x, y} \beta_{y}+6 c_{1}^{2} \beta_{y, y} \beta_{y}\right] \\
& \kappa_{1}^{n l 6}=\left[c_{1}^{2}\left(\theta_{y, x}\right)^{2}+c_{1}^{2}\left(\beta_{x, x}\right)^{2}+c_{1}^{2}\left(\theta_{x, x}\right)^{2}+c_{1}^{2}\left(\beta_{y, x}\right)^{2}\right. \\
& \left.+2 c_{1}^{2} \theta_{y, x} \beta_{x, x}-2 c_{1}^{2} \theta_{x, x} \beta_{y, x}\right], \\
& \kappa_{2}^{n l 6}=\left[c_{1}^{2}\left(\theta_{y, y}\right)^{2}+c_{1}^{2}\left(\beta_{x, y}\right)^{2}+c_{1}^{2}\left(\theta_{x, y}\right)^{2}+c_{1}^{2}\left(\beta_{y, y}\right)^{2}\right. \\
& \left.+2 c_{1}^{2} \theta_{y, y} \beta_{x, y}-2 c_{1}^{2} \theta_{x, y} \beta_{y, y}\right] \\
& \kappa_{6}^{n l 6}=\left[2 c_{1}^{2} \theta_{y, x} \theta_{y, y}+2 c_{1}^{2} \theta_{y, x} \beta_{x, y}+2 c_{1}^{2} \beta_{x, x} \theta_{y, y}\right. \\
& +2 c_{1}^{2} \beta_{x, x} \beta_{x, y}+2 c_{1}^{2} \theta_{x, x} \theta_{x, y}-2 c_{1}^{2} \theta_{x, x} \beta_{y, y} \\
& \left.-2 c_{1}^{2} \beta_{y, x} \theta_{x, y}+2 c_{1}^{2} \beta_{y, x} \beta_{y, y}\right], \\
& \kappa_{5}^{n l 6}=0, \quad \kappa_{4}^{n l 6}=0 .
\end{aligned}
$$

The linear $\left[H_{L}\right]$ and nonlinear $\left[H_{N L}\right]$ thickness matrices are calculated by Eq. (A.2.3) as shown in Box I.

Inertia Matrix [I]:

$$
\begin{array}{ll}
{[I]_{1,1}=I_{0},} & {[I]_{2,2}=I_{0}, \quad[I]_{3,3}=I_{0},} \\
{[I]_{4,4}=c_{1}^{2} \times I_{6},} & {[I]_{4,7}=-c_{1} \times J_{4},} \\
{[I]_{5,5}=c_{1}^{2} \times I_{6},} & {[I]_{5,6}=c_{1} \times J_{4},} \\
{[I]_{6,5}=c_{1} \times J_{4},} & {[I]_{6,6}=K_{2},} \\
{[I]_{7,4}=-c_{1} \times J_{4},} & {[I]_{7,7}=K_{2},}
\end{array}
$$




$$
\begin{aligned}
& H_{L}= {\left[\begin{array}{ccccccccccccccccccccc}
1 & 0 & 0 & 0 & 0 & z & 0 & 0 & 0 & 0 & z^{2} & 0 & 0 & 0 & 0 & z^{3} & 0 & 0 & 0 & 0 \\
0 & 1 & 0 & 0 & 0 & 0 & z & 0 & 0 & 0 & 0 & z^{2} & 0 & 0 & 0 & 0 & z^{3} & 0 & 0 & 0 \\
0 & 0 & 1 & 0 & 0 & 0 & 0 & z & 0 & 0 & 0 & 0 & z^{2} & 0 & 0 & 0 & 0 & z^{3} & 0 & 0 \\
0 & 0 & 0 & 1 & 0 & 0 & 0 & 0 & z & 0 & 0 & 0 & 0 & z^{2} & 0 & 0 & 0 & 0 & z^{3} & 0 \\
0 & 0 & 0 & 0 & 1 & 0 & 0 & 0 & 0 & z & 0 & 0 & 0 & 0 & z^{2} & 0 & 0 & 0 & 0 & z^{3}
\end{array}\right], } \\
& H_{N L}=\left[\begin{array}{cccccccccccccccccccc}
1 & 0 & 0 & 0 & 0 & z & 0 & 0 & 0 & 0 & z^{2} & 0 & 0 & 0 & 0 & z^{3} & 0 & 0 & 0 & 0 \\
0 & 1 & 0 & 0 & 0 & 0 & z & 0 & 0 & 0 & 0 & z^{2} & 0 & 0 & 0 & 0 & z^{3} & 0 & 0 & 0 \\
0 & 0 & 1 & 0 & 0 & 0 & 0 & z & 0 & 0 & 0 & 0 & z^{2} & 0 & 0 & 0 & 0 & z^{3} & 0 & 0 \\
0 & 0 & 0 & 1 & 0 & 0 & 0 & 0 & z & 0 & 0 & 0 & 0 & z^{2} & 0 & 0 & 0 & 0 & z^{3} & 0 \\
0 & 0 & 0 & 0 & 1 & 0 & 0 & 0 & 0 & z & 0 & 0 & 0 & 0 & z^{2} & 0 & 0 & 0 & 0 & z^{3} \\
& 0 & 0 & z^{5} & 0 & 0 & 0 & 0 & z^{6} & 0 & 0 & 0 & 0 \\
0 & 0 & 0 & z^{5} & 0 & 0 & 0 & 0 & z^{6} & 0 & 0 & 0 \\
0 & 0 & 0 & 0 & z^{5} & 0 & 0 & 0 & 0 & z^{6} & 0 & 0 \\
& z^{4} & 0 & 0 & 0 & 0 & z^{5} & 0 & 0 & 0 & 0 & z^{6} & 0 \\
0 & z^{4} & 0 & 0 & 0 & 0 & z^{5} & 0 & 0 & 0 & 0 & z^{6}
\end{array}\right] . \\
&
\end{aligned}
$$$$
H_{N L}=\left[\begin{array}{ccccccccccccccccccccccc}
1 & 0 & 0 & 0 & 0 & z & 0 & 0 & 0 & 0 & z^{2} & 0 & 0 & 0 & 0 & z^{3} & 0 & 0 & 0 & 0 & z^{4} & 0 & 0 \\
0 & 1 & 0 & 0 & 0 & 0 & z & 0 & 0 & 0 & 0 & z^{2} & 0 & 0 & 0 & 0 & z^{3} & 0 & 0 & 0 & 0 & z^{4} & 0 \\
0 & 0 & 1 & 0 & 0 & 0 & 0 & z & 0 & 0 & 0 & 0 & z^{2} & 0 & 0 & 0 & 0 & z^{3} & 0 & 0 & 0 & 0 & z^{4} \\
0 & 0 & 0 & 1 & 0 & 0 & 0 & 0 & z & 0 & 0 & 0 & 0 & z^{2} & 0 & 0 & 0 & 0 & z^{3} & 0 & 0 & 0 & 0 \\
0 & 0 & 0 & 0 & 1 & 0 & 0 & 0 & 0 & z & 0 & 0 & 0 & 0 & z^{2} & 0 & 0 & 0 & 0 & z^{3} & 0 & 0 & 0
\end{array}\right.
$$

Box I

where:

$$
\begin{array}{rlrl}
I_{i} & =\int_{-h / 2}^{h / 2} \rho z^{i} d z, & & (i=0,2,4,6), \\
c_{1} & =\frac{4}{3 h^{2}}, & K_{2}=I_{2}-2 c_{1} J_{4}+c_{1}^{2} I_{6}, \\
J_{4} & =I_{4}-c_{1} I_{6} . &
\end{array}
$$

The work done due to nonlinear temperature rise $W_{\Delta T}$ :

$$
W_{\Delta T}=\int_{-h / 2}^{h / 2}\left\{\varepsilon_{G}\right\}^{t r}[S]\left\{\varepsilon_{G}\right\}
$$

where:

$$
\left\{\varepsilon_{G}\right\}=\frac{1}{2}\left[\begin{array}{c}
\left\{u_{, x}^{2}+v_{, x}^{2}+w_{, x}^{2}\right\} \\
\left\{u_{, y}^{2}+v_{, y}^{2}+w_{, y}^{2}\right\} \\
2\left\{u_{, x} u_{, y}+v_{, x} v_{, y}+w_{, x} w_{, y}\right\}
\end{array}\right]
$$

or:

$$
\left\{\varepsilon_{G}\right\}=[H]\left[A_{g}\right][\aleph]=\left[B_{G}\right]\{\delta\},
$$$$
[H]=\left[\begin{array}{ccccccc}
1 & 0 & 0 & -c_{1} z^{3} & 0 & 0 & z-c_{1} z^{3} \\
0 & 1 & 0 & 0 & -c_{1} z^{3} & z-c_{1} z^{3} & 0 \\
0 & 0 & 1 & 0 & 0 & 0 & 0
\end{array}\right],
$$$$
\left[A_{g}\right]=\left[\begin{array}{c}
\left\{u_{, x}+v_{, x}+w_{, x}\right\} \\
\left\{u_{, y}+v_{, y}+w_{, y}\right\} \\
\left\{u_{, x} u_{, y}+v_{, x} v_{, y}+w_{, x} w\right\}
\end{array}\right], \quad[\aleph]=\left[\begin{array}{c}
u_{, x} \\
u_{, y} \\
v_{, x} \\
v_{, y} \\
w_{, x} \\
w_{, y}
\end{array}\right]
$$

$$
[S]=\left[\begin{array}{cccccc}
N_{x}^{T} & N_{x y}^{T} & 0 & 0 & 0 & 0 \\
N_{x y}^{T} & N_{y}^{T} & 0 & 0 & 0 & 0 \\
0 & 0 & N_{x}^{T} & N_{x y}^{T} & 0 & 0 \\
0 & 0 & N_{x y}^{T} & N_{y}^{T} & 0 & 0 \\
0 & 0 & 0 & 0 & N_{x}^{T} & N_{x y}^{T} \\
0 & 0 & 0 & 0 & N_{x y}^{T} & N_{y}^{T}
\end{array}\right] .
$$

Terms of $\left[A_{g}\right]$ matrix:

$$
\begin{aligned}
& {\left[A_{g}\right]_{1,1}=u_{, x}, \quad\left[A_{g}\right]_{1,3}=v_{, x}, \quad\left[A_{g}\right]_{1,5}=w_{, x},} \\
& {\left[A_{g}\right]_{2,2}=u_{, y}, \quad\left[A_{g}\right]_{2,4}=v_{, y}, \quad\left[A_{g}\right]_{2,6}=w_{, y},} \\
& {\left[A_{g}\right]_{3,1}=u_{, y}, \quad\left[A_{g}\right]_{3,2}=u_{, x}, \quad\left[A_{g}\right]_{3,3}=v_{, y},} \\
& {\left[A_{g}\right]_{3,4}=v_{, x}, \quad\left[A_{g}\right]_{3,5}=w_{, y}, \quad\left[A_{g}\right]_{3,6}=w_{, x},} \\
& {\left[A_{g}\right]_{4,1}=\theta_{y}, \quad\left[A_{g}\right]_{4,3}=-\theta_{x}, \quad\left[A_{g}\right]_{4,17}=v_{, x},} \\
& {\left[A_{g}\right]_{4,18}=u_{, x}, \quad\left[A_{g}\right]_{5,2}=\theta_{y}, \quad\left[A_{g}\right]_{5,4}=-\theta_{x},} \\
& {\left[A_{g}\right]_{5,17}=-v_{, y}, \quad\left[A_{g}\right]_{5,18}=u_{, y},} \\
& {\left[A_{g}\right]_{6,1}=\theta_{y, x}, \quad\left[A_{g}\right]_{6,3}=-\theta_{x, x},} \\
& {\left[A_{g}\right]_{6,11}=-v, x, \quad\left[A_{g}\right]_{6,13}=u_{, x},} \\
& {\left[A_{g}\right]_{7,2}=\theta_{y, y}, \quad\left[A_{g}\right]_{7,4}=-\theta_{x, y},} \\
& {\left[A_{g}\right]_{7,12}=-v_{, y}, \quad\left[A_{g}\right]_{7,14}=u_{, y},} \\
& {\left[A_{g}\right]_{8,1}=\theta_{y, y}, \quad\left[A_{g}\right]_{8,2}=\theta_{y, x},}
\end{aligned}
$$




$$
\begin{aligned}
& {\left[A_{g}\right]_{8,3}=-\theta_{x, y}, \quad\left[A_{g}\right]_{8,4}=-\theta_{x, x}, \quad\left[A_{g}\right]_{17,12}=-c_{1} \times v_{, y}, \quad\left[A_{g}\right]_{17,14}=-c_{2} \times u_{, y},} \\
& {\left[A_{g}\right]_{8,11}=-v_{, y}, \quad\left[A_{g}\right]_{8,12}=-v_{, x}, \quad\left[A_{g}\right]_{18,1}=-c_{1} \times \theta_{y, y}-c_{1} \times \beta_{x, y},} \\
& {\left[A_{g}\right]_{8,13}=u_{, y}, \quad\left[A_{g}\right]_{8,14}=u_{, x}, \quad\left[A_{g}\right]_{18,2}=-c_{1} \times \theta_{y, x}-c_{1} \times \beta_{x, x},} \\
& {\left[A_{g}\right]_{9,11}=\theta_{x}, \quad\left[A_{g}\right]_{9,13}=\theta_{y}, \quad\left[A_{g}\right]_{18,3}=c_{1} \times \theta_{x, y}-c_{1} \times \beta_{y, y},} \\
& {\left[A_{g}\right]_{9,17}=\theta_{x, x}, \quad\left[A_{g}\right]_{9,18}=\theta_{y, x}} \\
& {\left[A_{g}\right]_{10,12}=\theta_{x}, \quad\left[A_{g}\right]_{10,14}=\theta_{y},} \\
& {\left[A_{g}\right]_{10,17}=\theta_{x, y}, \quad\left[A_{g}\right]_{10,18}=\theta_{y, y},} \\
& {\left[A_{g}\right]_{11,11}=\theta_{x, x}, \quad\left[A_{g}\right]_{11,13}=\theta_{y, x},} \\
& {[A]_{12,12}=\theta_{x, y}, \quad[A]_{12,14}=\theta_{y, y},} \\
& {[A]_{13,11}=\theta_{x, y}, \quad[A]_{13,12}=\theta_{x, x},} \\
& {[A]_{13,13}=\theta_{y, y}, \quad\left[A_{g}\right]_{13,14}=\theta_{y, x},} \\
& {\left[A_{g}\right]_{14,1}=-c_{2} \times \theta_{y}-c_{2} \times \beta_{x},} \\
& {[A]_{14,3}=c_{2} \times \theta_{x}-c_{2} \times \beta_{y},} \\
& {[A]_{14,15}=-c_{2} \times u_{, x}, \quad[A]_{14,16}=-c_{2} \times v_{, x}} \\
& {\left[A_{g}\right]_{14,17}=c_{2} \times v_{, x}, \quad\left[A_{g}\right]_{14,18}=-c_{2} \times u_{, x},} \\
& {[A]_{15,2}=-c_{2} \times \theta_{y}-c_{2} \times \beta_{x},} \\
& {[A]_{15,4}=c_{2} \times \theta_{x}-c_{2} \times \beta_{y},} \\
& {[A]_{15,15}=-c_{2} \times u_{, y}, \quad\left[A_{g}\right]_{15,16}=-c_{2} \times v_{, y},} \\
& {\left[A_{g}\right]_{15,17}=c_{2} \times v_{, y}, \quad[A]_{15,18}=-c_{2} \times u_{, y},} \\
& {[A]_{16,1}=-c_{1} \times \beta_{x, x}-c_{1} \times \theta_{y, x},} \\
& {\left[A_{g}\right]_{16,3}=c_{1} \times \theta_{x, x}-c_{1} \times \beta_{y, x},} \\
& {\left[A_{g}\right]_{16,7}=-c_{1} \times u_{, x}, \quad\left[A_{g}\right]_{16,9}=c_{1} \times v_{, x},} \\
& {\left[A_{g}\right]_{16,11}=c_{1} \times v_{, x}, \quad\left[A_{g}\right]_{16,13}=-c_{1} \times u_{, x},} \\
& {\left[A_{g}\right]_{17,2}=-c_{1} \times \theta_{y, y}-c_{1} \times \beta_{x, y},} \\
& {\left[A_{g}\right]_{17,4}=-c_{1} \times \beta_{y, y}+c_{1} \times \theta_{x, y}, \quad\left[A_{g}\right]_{21,11}=c_{1} \times \beta_{y, x}-2 c_{1} \times \theta_{x, x},} \\
& {\left[A_{g}\right]_{17,8}=-c_{1} \times u_{, y}, \quad\left[A_{g}\right]_{17,10}=-c_{1} \times v_{, y}, \quad\left[A_{g}\right]_{21,13}=-c_{1} \times \beta_{x, x}-2 c_{1} \times \theta_{y, x},} \\
& {\left[A_{g}\right]_{18,4}=c_{1} \times \theta_{x, x}-c_{1} \times \beta_{y, x}} \\
& {\left[A_{g}\right]_{18,7}=-c_{1} \times u_{, y}, \quad\left[A_{g}\right]_{18,8}=-c_{1} \times u_{, x}} \\
& {\left[A_{g}\right]_{18,9}=-c_{1} \times v_{, y}, \quad\left[A_{g}\right]_{18,10}=-c_{1} \times v_{, x}} \\
& {\left[A_{g}\right]_{18,11}=c_{1} \times v_{, y}, \quad\left[A_{g}\right]_{18,12}=c_{1} \times v_{, x},} \\
& {\left[A_{g}\right]_{18,13}=-c_{1} \times u_{, y}, \quad\left[A_{g}\right]_{18,14}=-c_{1} \times u_{, x},} \\
& {\left[A_{g}\right]_{19,7}=-c_{1} \times \theta_{y}, \quad\left[A_{g}\right]_{19,9}=c_{1} \times \theta_{x},} \\
& {\left[A_{g}\right]_{19,11}=-4 \times c_{1} \times \theta_{x}-c_{2} \times \beta_{y},} \\
& {\left[A_{g}\right]_{19,13}=-4 \times c_{1} \times \theta_{y}-c_{2} \times \beta_{x},} \\
& {\left[A_{g}\right]_{19,15}=-c_{2} \times \theta_{y, x}, \quad\left[A_{g}\right]_{19,16}=-c_{2} \times \theta_{x, x}} \\
& {\left[A_{g}\right]_{19,17}=-4 \times c_{1} \times \theta_{x, x}+c_{1} \times \beta_{y, x},} \\
& {\left[A_{g}\right]_{19,18}=-4 \times c_{1} \times \theta_{y, x}-c_{1} \times \beta_{x, x},} \\
& {\left[A_{g}\right]_{20,8}=-c_{1} \times \theta_{y}, \quad\left[A_{g}\right]_{20,10}=c_{1} \times \theta_{x},} \\
& {\left[A_{g}\right]_{20,12}=-4 \times c_{1} \times \theta_{x}+c_{2} \times \beta_{y},} \\
& {\left[A_{g}\right]_{20,14}=-4 \times c_{1} \times \theta_{y}-c_{2} \times \beta_{x},} \\
& {\left[A_{g}\right]_{20,15}=-c_{2} \times \theta_{y, y}, \quad\left[A_{g}\right]_{20,16}=c_{2} \times \theta_{x, y},} \\
& {\left[A_{g}\right]_{20,17}=-4 \times c_{1} \times \theta_{x, y}+c_{1} \times \beta_{y, y},} \\
& {\left[A_{g}\right]_{20,18}=-4 \times c_{1} \times \theta_{y, y}-c_{1} \times \beta_{x, y},} \\
& {\left[A_{g}\right]_{21,7}=-c_{1} \times \theta_{y, x}, \quad\left[A_{g}\right]_{21,9}=c_{1} \times \theta_{x, x},}
\end{aligned}
$$




$$
\begin{array}{ll}
{\left[A_{g}\right]_{22,8}=-c_{1} \times \theta_{y, y}, \quad\left[A_{g}\right]_{22,10}=c_{1} \times \theta_{x, y},} & {\left[A_{g}\right]_{32,10}=c_{1}^{2} \times \beta_{y, y}-c_{1}^{2} \times \theta_{x, y},} \\
{\left[A_{g}\right]_{22,12}=-2 c_{1} \times \theta_{x, y}+c_{1} \times \beta_{y, y},} & {\left[A_{g}\right]_{32,12}=-c_{1}^{2} \times \beta_{y, y}+c_{1}^{2} \times \theta_{x, y},} \\
{\left[A_{g}\right]_{22,14}=-2 c_{1} \times \theta_{y, y}-c_{1} \times \beta_{x, y},} & {\left[A_{g}\right]_{32,14}=c_{1}^{2} \times \beta_{x, y}+c_{1}^{2} \times \theta_{y, y},} \\
{\left[A_{g}\right]_{23,7}=-c_{1} \times \theta_{y, y}, \quad\left[A_{g}\right]_{23,8}=-c_{1} \times \theta_{y, x},} & {\left[A_{g}\right]_{33,7}=c_{1}^{2} \times \beta_{x, y}+c_{1}^{2} \times \theta_{y, y},} \\
{\left[A_{g}\right]_{23,9}=c_{1} \times \theta_{x, y}, \quad\left[A_{g}\right]_{23,10}=c_{1} \times \theta_{x, x},} & {\left[A_{g}\right]_{33,8}=c_{1}^{2} \times \beta_{x, x}+c_{1}^{2} \times \theta_{y, x},} \\
{\left[A_{g}\right]_{23,11}=-2 c_{1} \times \theta_{x, y}+c_{1} \times \beta_{y, y},} & {\left[A_{g}\right]_{33,9}=c_{1}^{2} \times \beta_{y, y}-c_{1}^{2} \times \theta_{y, x},} \\
{\left[A_{g}\right]_{23,12}=-2 c_{1} \times \theta_{x, x}+c_{1} \times \beta_{y, x},} & {\left[A_{g}\right]_{33,10}=c_{1}^{2} \times \beta_{y, x}-c_{1}^{2} \times \theta_{x, x},} \\
{\left[A_{g}\right]_{23,13}=-2 c_{1} \times \theta_{y, y}-c_{1} \times \beta_{x, y},} & {\left[A_{g}\right]_{33,11}=-c_{1}^{2} \times \beta_{y, y}+c_{1}^{2} \times \theta_{x, y},} \\
{\left[A_{g}\right]_{23,14}=-2 c_{1} \times \theta_{y, x}-c_{1} \times \beta_{x, x},} & {\left[A_{g}\right]_{33,12}=-c_{1}^{2} \times \beta_{y, x}+c_{1}^{2} \times \theta_{x, x},} \\
{\left[A_{g}\right]_{29,7}=c_{2} c_{1} \times \theta_{y}+c_{2} c_{1} \times \beta_{x},} & {\left[A_{g}\right]_{33,14}=c_{1}^{2} \times \beta_{x, y}+c_{1}^{2} \times \theta_{y, y} .}
\end{array}
$$$$
\left[A_{g}\right]_{29,9}=-c_{2} c_{1} \times \theta_{x}+c_{2} c_{1} \times \beta_{y},
$$$$
\left[A_{g}\right]_{29,11}=c_{2} c_{1} \times \theta_{x}-c_{2} c_{1} \times \beta_{y},
$$$$
\left[A_{g}\right]_{29,13}=c_{2} c_{1} \times \theta_{y}+c_{2} c_{1} \times \beta_{x},
$$$$
\left[A_{g}\right]_{29,15}=c_{2} c_{1} \times \theta_{y, x}+c_{2} c_{1} \times \beta_{x, x},
$$$$
\left[A_{g}\right]_{29,16}=-c_{2} c_{1} \times \theta_{x, x}+c_{2} c_{1} \times \beta_{y, x},
$$$$
\left[A_{g}\right]_{29,17}=c_{2} c_{1} \times \theta_{x, x}-c_{2} c_{1} \times \beta_{y, x},
$$$$
\left[A_{g}\right]_{29,18}=c_{2} c_{1} \times \theta_{y, x}+c_{2} c_{1} \times \beta_{x, x},
$$$$
\left[A_{g}\right]_{30,8}=c_{2} c_{1} \times \theta_{y}+c_{2} c_{1} \times \beta_{x},
$$$$
\left[A_{g}\right]_{30,10}=-c_{2} c_{1} \times \theta_{x}+c_{2} c_{1} \times \beta_{y},
$$$$
\left[A_{g}\right]_{30,12}=c_{2} c_{1} \times \theta_{x}-c_{2} c_{1} \times \beta_{y},
$$$$
\left[A_{g}\right]_{30,14}=c_{2} c_{1} \times \theta_{y}+c_{2} c_{1} \times \beta_{x},
$$$$
\left[A_{g}\right]_{30,15}=c_{2} c_{1} \times \theta_{y, y}+c_{2} c_{1} \times \beta_{x, y},
$$$$
\left[A_{g}\right]_{30,16}=-c_{2} c_{1} \times \theta_{x, y}+c_{2} c_{1} \times \beta_{y, y},
$$$$
\left[A_{g}\right]_{30,17}=c_{2} c_{1} \times \theta_{x, y}-c_{2} c_{1} \times \beta_{y, y},
$$$$
\left[A_{g}\right]_{30,18}=c_{2} c_{1} \times \theta_{y, y}+c_{2} c_{1} \times \beta_{x, y},
$$$$
\left[A_{g}\right]_{31,7}=c_{1}^{2} \times \beta_{x, x}+c_{1}^{2} \times \theta_{y, x},
$$$$
\left[A_{g}\right]_{31,9}=c_{1}^{2} \times \beta_{y, x}-c_{1}^{2} \times \theta_{x, x},
$$$$
\left[A_{g}\right]_{31,11}=-c_{1}^{2} \times \beta_{y, x}+c_{1}^{2} \times \theta_{x, x},
$$$$
\left[A_{g}\right]_{31,13}=c_{1}^{2} \times \beta_{x, x}+c_{1}^{2} \times \theta_{y, x},
$$$$
\left[A_{g}\right]_{32,8}=c_{1}^{2} \times \beta_{x, y}+c_{1}^{2} \times \theta_{y, y},
$$

Terms of $\left[B_{G}\right]$ matrix:

$$
\begin{array}{ll}
{\left[B_{G}\right]_{1,1}=\partial / \partial x,} & {\left[B_{G}\right]_{2,2}=\partial / \partial y,} \\
{\left[B_{G}\right]_{3,1}=\partial / \partial y,} & {\left[B_{G}\right]_{3,2}=\partial / \partial x,} \\
{\left[B_{G}\right]_{4,3}=\partial / \partial x,} & {\left[B_{G}\right]_{4,7}=1,} \\
{\left[B_{G}\right]_{5,3}=\partial / \partial y,} & {\left[B_{G}\right]_{5,6}=-1,} \\
{\left[B_{G}\right]_{6,7}=\partial / \partial x,} & {\left[B_{G}\right]_{7,6}=-\partial / \partial y,} \\
{\left[B_{G}\right]_{8,6}=-\partial / \partial x,} & {\left[B_{G}\right]_{8,7}=\partial / \partial y,} \\
{\left[B_{G}\right]_{14,4}=-c_{2},} & {\left[B_{G}\right]_{14,7}=-c_{2},} \\
{\left[B_{G}\right]_{15,5}=-c_{2},} & {\left[B_{G}\right]_{15,6}=c_{2},} \\
{\left[B_{G}\right]_{16,4}=-c_{1} \times \partial / \partial x,} & {\left[B_{G}\right]_{16,7}=-c_{1} \times \partial / \partial x,} \\
{\left[B_{G}\right]_{17,5}=-c_{1} \times \partial / \partial y,} & {\left[B_{G}\right]_{17,6}=c_{1} \times \partial / \partial y,} \\
{\left[B_{G}\right]_{18,4}=-c_{1} \times \partial / \partial y,} & {\left[B_{G}\right]_{18,5}=-c_{1} \times \partial / \partial x,} \\
{\left[B_{G}\right]_{18,6}=c_{1} \times \partial / \partial x,} & {\left[B_{G}\right]_{18,7}=-c_{1} \times \partial / \partial y .}
\end{array}
$$

Terms of $[\aleph]$ matrix:
$[\aleph]_{1,1}=\partial / \partial x, \quad[\aleph]_{2,1}=\partial / \partial y$,
$[\aleph]_{3,2}=\partial / \partial x, \quad[\aleph]_{4,2}=\partial / \partial y$,
$[\aleph]_{5,3}=\partial / \partial x, \quad[\aleph]_{6,3}=\partial / \partial y$,
$[\aleph]_{7,4}=\partial / \partial x, \quad[\aleph]_{8,4}=\partial / \partial y$,
$[\aleph]_{9,5}=\partial / \partial x, \quad[\aleph]_{10,5}=\partial / \partial y$,
$[\aleph]_{11,6}=\partial / \partial x, \quad[\aleph]_{12,6}=\partial / \partial y$, 


$$
\begin{array}{ll}
{[\aleph]_{13,7}=\partial / \partial x,} & {[\aleph]_{14,7}=\partial / \partial y,} \\
{[\aleph]_{15,4}=1,} & {[\aleph]_{16,5}=1,} \\
{[\aleph]_{17,6}=1,} & {[\aleph]_{18,7}=1 .}
\end{array}
$$

\section{Biographies}

Smita Parida completed her BTech in Mechanical Engineering from IGIT, Sarang in 2011 and Master degree in CAD/CAM in 2012 from Central Tool Room and Training Centre, Bhubaneswar. Currently, she is pursuing her PhD from National Institute of Technology, Rourkela, India. Her research interests include the areas of solid mechanics, functionally graded materials, finite element modeling, and nonlinear analysis.

Sukesh Chandra Mohanty received his BSc degree in Mechanical Engineering from UCE(VSSUT) Burla and MTech degree in Mechanical Engineering from IIT (Banaras Hindu University), India. He received his $\mathrm{PhD}$ degree from National Institute of Technology (NIT), Rourkela, India. Currently, he is an Associate Professor at the Department of Mechanical Engineering at NIT, Rourkela, India. His research interests include the stability of structures, vibration control, and gear dynamics. He is a member of Institution of Engineers, India. 